\title{
Circulation and water mass transports on the East Antarctic shelf in the Mertz Glacier region
}

\author{
Martin Antoine ${ }^{1,{ }^{*}}$, Houssais Marie-Noëlle ${ }^{1}$, Goff Hervé Le ${ }^{1}$, Marec Claudie ${ }^{2}$, Dausse Denis ${ }^{1}$ \\ ${ }^{1}$ Sorbonne Universités (UPMC, Univ Paris-06)-CNRS-IRD-MNHN, LOCEAN laboratory, 4 place \\ Jussieu, F-75005 Paris, France \\ ${ }_{2}^{2}$ Laboratoire d'Océanographie Physique et Spatiale, IFREMER- Centre de Brest, CS 10070, 29280 \\ Plouzané, France \\ * Corresponding author : Antoine Martin, email address : antoine martin@orange.fr
}

\begin{abstract}
:
The East Antarctic shelf off Adélie-George $V$ Land is known to be an important region for Dense Shelf Water (DSW) formation as a result of intense sea ice production in the Mertz Glacier Polynya during the winter season. It is also a region where the warm modified Circumpolar Deep Water (mCDW) penetrates onto the shelf during the summer. Using hydrographic observations from a summer survey in 2008 we implement a box inverse model to propose a comprehensive view of the steady state circulation on this shelf in summer. Additional information from mooring observations collected on the depression slope is used to provide context to the retrieved circulation scheme. Over the depression slope, the summer baroclinic structure of the currents is found to contrast with the almost barotropic structure in winter.
\end{abstract}

The summer circulation is strongly constrained by the DSW distribution and forms a clockwise circulation primarily transporting the fresh surface waters and the warm mCDW around the dome of DSW. Over the upper flank of the Mertz Bank, the inflow branch transports the mCDW towards the Mertz Glacier, while, over the lower part of the slope, the outflow branch returns to the sill a diluted mode of the same water mass. A total of $0.19 \mathrm{~Sv}$ of mCDW inflows at the sill and two-third reach the Mertz Glacier and recirculate in front of it, allowing the mCDW to penetrate into the deeper part of the depression. Possible scenarios of interaction between the mCDW and the DSW with the glacier are examined. It is shown that, despite the water mass pathways and transports suggest possible ice-ocean interaction, both lateral and basal melting were likely small in summer 2008 . Finally, our results suggest that, in addition to bathymetric features, the distribution of the residual DSW which is left from the preceding winter sets up regional pressure gradients which provide a seasonal control on the shelf circulation. In particular, the spring collapse of the convective patch would contribute to setting up a deep pycnocline which strongly impacts the shelf circulation in the following summer, with possible feedback of the mCDW transports on the polynya activity and water mass formation. 


\section{Highlights}

- A new circulation scheme based on inverse modelling method is proposed. The spring collapse of the convective patch would contribute to setting up a deep pycnocline which strongly impacts the shelf circulation in the following summer. The mechanism could induce a possible feedback of the mCDW transports on the polynya activity and water mass formation.

Keywords: Antarctica, Continental shelf, Modified Circumpolar Deep Water, Heat transport, Freshwater transport, Adélie Georges V Land

\section{Introduction}

As a region of intense transformation of ocean water masses and strong interaction with the Antarctic ice sheet, the Antarctic shelf is recognized as a region of upmost importance for the ocean and Earth climate. Saline, dense shelf waters (DSW) formed in the coastal polynyas around the Antarctic continent (Zwally et al., 1985; Cavalieri and Martin, 1985) are considered instrumental to the formation of the Antarctic Bottom Water (AABW), the densest water mass of the world ocean (Jacobs et al., 1970; Gordon, 1971; Gill , 1973; Orsi et al., 1999). As such, the AABW properties are largely controlled by the formation, transport and mixing processes occurring on the Antarctic shelf. Shelf ocean processes also play a crucial role in the evolution of the Antarctic ice sheet (Jacobs et al., 1996; Rignot, 2002). Heat supplied by the shelf waters to the underside of the oating glaciers and ice shelves is thought to exert an important control on the current evolution of the mass balance of the ice sheet (Pritchard et al., 
2012; Rignot et al., 2013; Liu et al. 2015), and consequently on the amount of melt water released to the ocean, with strong implications for the ocean fresh water budget and deep water properties $(J a c o b s$, 2006 Purkey and Johnson, 2013), sea ice distribution (Bintanja et al., 2013) and sea level rise (Rignot

15 et al. 2011). As importantly, the numerous interactions taking place on the Antarctic shelf, including the large influence of the seasonal ice zone on the water mass circulation and properties, help maintain specific ice-dependent ecosystems which are essential links to the Southern Ocean marine food web $\sqrt{N i c o l}$ et al. 2000)

Large regional differences exist between the different regions of the Antarctic shelf as a result of contrasted shelf geometry and topography, atmospheric forcing (Jacobs, 2006, Spence et al. 2014, Gordon et al. 2015), land and sea ice environment or cross-shelf geometry of the front separating the cold shelf waters from the warmer deep ocean waters $($ Jacobs, $1991 ;$ Whitworth et al. 1998, Jacobs, 2004; Schmidtko et al. 2014). Much of the effort for understanding the Antarctic shelf circulation and cross shelf exchanges have however concentrated on regions which were identified as particularly vulnerable to climate change,

25 such as the Antarctic Peninsula (e.g. Martinson et al., 2008, Moffat et al., 2009, Dinniman et al., 2011) or recognized as important sites of ocean ice shelf interactions, such as the Amundsen Sea (e.g. Ha et al. 2014) or DSW production, such as the Weddell Sea (e.g. Carmack and Foster, 1975, Foldvik et al., 2001. Darelius et al. 2014) and the Ross Sea (e.g. Jacobs et al., 1970, Smith et al., 2014). Less is known about the circulation and processes occurring in the Indian Ocean- Australian sectors of the Antarctic shelf

30 where observations are less numerous. Yet, the continental shelf to the south of the Australian-Antarctic Basin is known to host important sources of dense shelf waters which contribute to AABW renewal. Among these, the dense water formed off the Adélie-George V Land (AGVL) is the precursor of the Adélie Land Bottom Water (ALBW, Gordon and Tchernia, 1972), one of the four main source water masses contributing to the AABW (Rintoul, 1998;| Meredith, 2013). Interest for the AGVL shelf region

35 has increased after observations spanning the last decades revealed significant freshening of the bottom waters of the Australian-Antarctic Basin (AAB) (Aoki et al., 2005, Rintoul, 2007, Aoki et al., 2013), one of the three major reservoirs of AABW. These changes were conjectured to reflect variations in the properties and/or export volume of the source shelf waters collecting into the basin which are essentially located off the AGVL (ALBW) and in the Ross Sea (e.g. Orsi et al. 1999 , Bindoff et al., 2000, Orsi, 402010 .

The present study focuses on characterizing the shelf circulation off the AGVL. By taking benefit of an intensive hydrographic cruise carried out in summer 2008 (Lacarra et al., 2011 ) and supplemented by mooring instruments which recorded current velocities and hydrographic properties over complete annual cycles, we aim at documenting the summer regional circulation on the shelf in order to better 45 understand its role in the spatial and temporal distributions of the water masses, in particular the $\mathrm{mCDW}$ which is recurrently observed on the AGVL shelf in summer (Jacobs, 1989, Rintoul, 1998; Lacarra et al. 2011), the implications for the cross shelf exchanges and ocean-glacier interactions. The region considered in this study mainly consists of a ca. $100 \mathrm{~km}$ wide shelf extending between $142^{\circ} \mathrm{E}$ and $146^{\circ} \mathrm{E}$, from the Antarctic coast to the shelf break at a latitude of about $65^{\circ} 50^{\prime} \mathrm{S}$ (Figure 1). The shelf bottom topography 50 (Beaman et al. 2011) delineates a deep depression, the Adélie Depression, with maximum depth of ca. $1300 \mathrm{~m}$ reached near the coast. The depression is bordered by shallow (200 $\mathrm{m}$ deep) banks on both its northeastern and western sides, and shoals toward the shelf break where a $420 \mathrm{~m}$ deep sill, the Adélie Sill, separates the shelf from the offshore slope region. Observational evidence and numerical model results suggest that in this latitudinal band a cyclonic gyre circulation exists (Bindoff et al., 2000, Aoki et al.

55 2010), although the exact extent and volume transport of the gyre are largely unknown. This "subpolar gyre" is a transition region encompassing water masses, the Antarctic Surface Water (AASW) and the modified Circumpolar Deep Water (mCDW), which have access to the AGVL shelf (e.g. Orsi et al., 1995 , Whitworth et al., 1998). The southern branch of the AAB gyre is made by the westward flowing Antarctic Slope Current which is a major provider of mCDW intrusions onto the shelf (e.g. Bindoff et al. 2000 .

60 Williams et al. 2010, see Figure 1). The along-shelf distribution of the warm temperature anomalies associated with these intrusions is to some extent determined by the relative proximity of the Antarctic Slope Front (Williams et al. 2011). AASW is a widespread water mass extending on either side of the shelf break and includes a surface mixed layer with thickness and properties seasonally varying from a shallow (order $10 \mathrm{~m}$ ), warm and fresh layer in summer to a deep (order $100 \mathrm{~m}$ ), cold layer in winter.

${ }_{65}$ Remnants of the winter mixed layer, known as Winter Water (WW), are found in summer on the AGVL shelf as a subsurface temperature minimum underneath the warmed surface mixed layer and above the mCDW (e.g. Rintoul, 1998). 
The Adélie Depression is bounded to-the southeast by the Mertz Glacier Polynya (MGT) which, prior to its calving in February 2010, was a $140 \mathrm{~km}$ long, $35 \mathrm{~km}$ wide floating ice tongue, extending 70 northeastward and grounded at its front on the Mertz Bank. A wide polynya, the Mertz Glacier Polynya (MGP), develops in the lee of the MGT and is characterized by low winter sea ice concentrations, with enhanced signature in the coastal area and in the lee of the glacier (e.g. Dragon et al. 2014 ) and high ice production rates (Tamura et al. 2008$)$. The 2010 calving greatly modified the shape of the polynya, initiating a period of reduced open water area and ice production (Tamura et al. 2012 , Dragon et al.

2014). In the MGP, brines rejected in the ocean surface layer as a result of winter surface freezing and subsequent water column overturning lead to the formation of DSW in the depression, evidence of which is found throughout the year at the bottom of the depression (Williams and Bindoff, 2003, Lacarra et al. 2011). Interaction of the DSW with the MGT leads to formation of supercooled (with respect to surface freezing temperatures) Ice Shelf Water (ISW) which is found in summer along the MGT (e.g. Lacarra et al., 2011) but also in winter near the coast (Bindoff et al., 2001; Williams and Bindoff, 2003). The likely presence of the mCDW along the MGT would not preclude that this water mass could interact directly with the glacier (Jacobs, 1989), a scenario which is suggested by model simulations (Cougnon et al. 2013, Kusahara et al. 2017) but still needs to be identified from observations.

Water mass transformation on the shelf is expected to exert a strong dynamical control on the re85 gional circulation and water mass distribution and transports. In particular, the ability of the mCDW to flow onto the shelf depends to some extent on the density distribution which sets constraints on the potential vorticity gradients. This hypothesis was used by Cougnon et al. (2013) to suggest that years with low MGP activity would be characterized by enhanced melting of the MGT due to mCDW intruding closer to the glacier tongue. Such constraints are expected to be seasonally dependent. Accordingly, numerical models suggest seasonality in the circulation with the winter overturning circulation spinning down once the winter buoyancy forcing has shut down, and relaxing into a surface-intensified gyre circulation organized around the central Adélie Depression (Kusahara et al. 2011). Year-long hydrographic observations at the Adélie Sill show some seasonality in the DSW outflow with the strongest signature of this water found on the western side of the sill in winter and spring and on the eastern side in summer (Williams et al. 2010). In contrast to winter where the mCDW remains hung on the Mertz Bank (Williams and Bindoff, 2003), in summer, evidences of $\mathrm{mCDW}$ are ubiquitous in the form of discontinuous spatial features in the Adélie Sill region and in the inner depression (Figure 2), most particularly over its northeastern slope (Lacarra et al. 2011$)$. Recently, Snow et al. (2016), applying a box inverse model to a series of hydrographic measurements taken in different years in this region, highlighted the recurrence of a coastal current flowing from the MGT to the Adélie Sill. Despite these earlier studies, a three-dimensional view combining in a consistent way an estimate of the summer shelf circulation with the associate water mass distribution and modification in the Adélie Depression need to be ascertained. The present study aims at providing such a view while discussing the mechanisms controlling this circulation as well as implications for the heat and fresh water transports and for possible interactions with the MGT.

The present manuscript is organized as follows. Section 2 describes the data sets which have been used for the present analysis. In section 3 the methodologies used in our analysis are introduced, in particular the box inverse model framework which has been designed to reconstruct the summer circulation. In section 4 we present the results of our analysis : the current structure and seasonality based on mooring observations, the summer circulation based on the inverse model results and then the associated water mass budgets of the shelf, heat and fresh water transports. In section 5 , we discuss dynamical aspects of the circulation and their implications for glacier-ocean interactions. Conclusions are given in section 6 .

\section{Data}

\subsection{Oceanographic data}

\section{Shipborne summer hydrography}

Our analysis focuses on the MGT pre-calving years, mainly the summer 2008 (with additional information from summer 2009) as our dataset is the most complete during this year. Between January 10 and 19, 2008, as part of the ALBION project, a total of 66 CTD- $O_{2}$ casts extending from the surface to the bottom were carried out on board the S/V Astrolabe in the Adélie Depression and Adélie Sill regions 




Figure 1: Distribution of the hydrographic casts collected during the ALBION 2008 summer cruise and the three inverse model boxes (Sill box in blue, Depression box in red and Mertz box in green), superimposed on the shelf bathymetry (after Mayet et al. 2013, adapted from Beaman et al. 2011). The Mertz Glacier Tongue (MGT) is also plotted with its pre- and post-calving geometry. The black arrow shows the path of the Antarctic Slope Current (adapted from Bindoff et al. 2000) and the schematic exchanges across the Adélie Sill. Also shown are specific geographic features : the Mertz Bank (MB), the Commonwealth Bay (CB), the Watt Bay (WB) and the Buchanan Bay (BB) as well as the location of the MG mooring (red square with a yellow cross) and the Cape Denison AWS (yellow square with a red cross). Stations belonging to the Sill and Mertz sections are highlighted by white dots surrounded by blue and green circles, respectively. The nearest station pair relative to the MG mooring is highlighted in orange (see Figure 7 ).

(Lacarra et al. 2011). The casts were organized along sections running roughly perpendicular to the main topographic gradients (Figure 1. The internal Rossby radius $\left(R_{d}=\frac{N H}{|f|}\right.$, with $\mathrm{H}$ the water column thickness, $\mathrm{N}$ the mean Brunt-Väisälä frequency computed from our data and $\mathrm{f}$ the Coriolis parameter) was on the order of 4-16 km which was small compared with the cruise station spacing (in the range 7-40 km). Our CTD array therefore did not resolve the mesoscale dynamics. Additionally, we used observations collected during the CEAMARC AU0803 cruise on board the RSV Aurora Australis between December 22, 2007 and January 4, 2008 (Rosenberg and Rintoul, 2010) to characterize the summer shelf hydrographic properties on a larger span (the CEAMARC array extended farther offshore than the ALBION array) or to evaluate the seasonal trend during that period (the CEAMARC cruise started in the early summer 2008 prior to the ALBION cruise).

Mooring observations

\begin{tabular}{ccccccc}
\hline Location & \multirow{2}{*}{ Time period } & Water & ADCP & \multicolumn{3}{c}{ SBE37 levels } \\
& & depth & level & bottom & middle & upper \\
\hline $66^{\circ} 50.320^{\prime} \mathrm{S}-144^{\circ} 56.624^{\prime} \mathrm{E}$ & 19 jan $2008-15$ jan 2009 & $901 \mathrm{~m}$ & $898 \mathrm{~m}$ & $901 \mathrm{~m}$ & $594 \mathrm{~m}$ & $278 \mathrm{~m}$ \\
$66^{\circ} 50.117^{\prime} \mathrm{S}-144^{\circ} 56.772^{\prime} \mathrm{E}$ & 15 jan 2009-14 jan 2010 & $880 \mathrm{~m}$ & $877 \mathrm{~m}$ & $880 \mathrm{~m}$ & $546 \mathrm{~m}$ & $237 \mathrm{~m}$ \\
\hline
\end{tabular}

Table 1: Description of the MG mooring : location, time period, water depth, instruments (name and instrument level)

In addition to shipborne CTD casts, we used mooring data collected in 2008 and 2009 (in the precalving period) by moored instruments which provided information on the annual evolution of the currents and hydrographic properties at a site (MG) located on the inner shelf some $60 \mathrm{~km}$ away from the MGT in 878-945 m (depending on the year) water depth over the northeastern slope of the Adélie Depression (Figure 1 and 2 . 


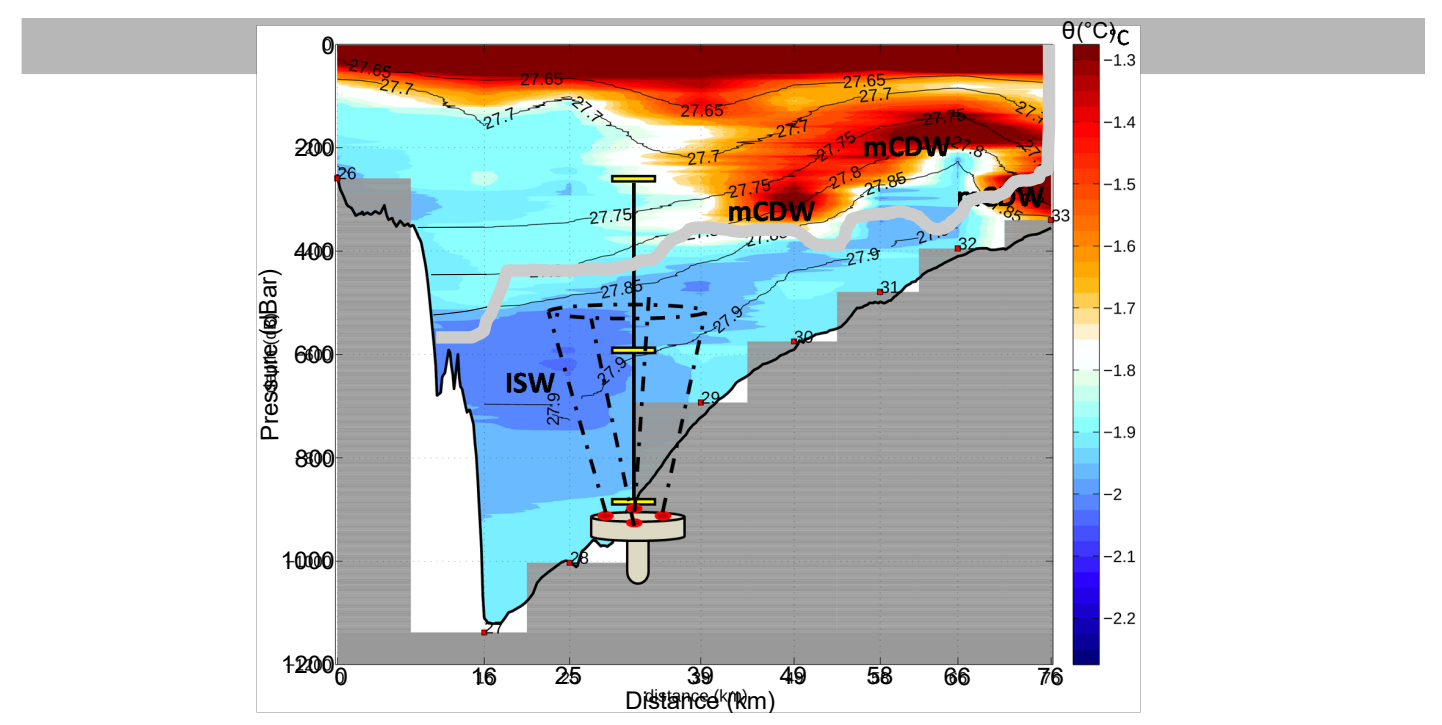

Figure 2: Potential temperature (color shading) and density (blacks contours) (referred to the surface) on a vertical section extending parallel to the Mertz Glacier Tongue, from the Buchanan Bay (left) to the Mertz Bank (right), during the ALBION 2008 cruise. The northeastern portion of the section corresponds to the Mertz section highlighted in Figure 1 . Also shown is the approximate location of the MG mooring on the Adélie Depression slope, with the upward looking bottom mounted ADCP and the three Microcats (yellow rectangles), and the draft of the MGT (from Mayet et al. 2013).

The mooring line was equipped with three SBE37 microcats distributed in the water column and a bottom mounted, upward-looking RDI $75 \mathrm{kHz}$ Long Ranger Acoustic Doppler Current Profiler (ADCP) (Table 1 and Figure 22. The microcat temperature, conductivity and pressure measurements were adjusted according to the factory pre- and post-deployment sensor calibration (see Lacarra et al. , 2014, for details about the measurement precision). All three parameters were recorded at a 7.5 minute sampling interval.

The ADCP data were quality checked using standard Teledyne RD Instruments criteria. Data were acquired every 2.5 minute and averaged over 1 hour-ensembles and over $14 \mathrm{~m}$ thick vertical bins spanning the water column from the near bottom to an upper limit varying according to the instrument performance. The latter was affected by the particle backscatter in the water column which showed a strong variability through the annual cycle. Typically, a mean annual vertical range of ca. $400 \mathrm{~m}$ from the bottom was found with a seasonal variation of $+/-100 \mathrm{~m}$ between a maximum in April-May and a minimum in January.

Due to the proximity of the magnetic South Pole, the ADCP compass was considered unreliable (e.g. Williams et al. (2008). To facilitate the a-posteriori estimate of the current heading, the ADCP was fixed in a frame anchored to the ocean bottom so that its horizontal orientation remained constant. Current velocities were measured relative to this fixed instrument coordinate system. Headings of the principal axis of the tidal constituent ellipses from a regional simulation with the high resolution T-UGOm tidal model (Mayet et al. 2013) were then used to retrieve an optimal estimate (in the least square sense) of the bottom frame orientation (see Appendix A for more details).

Since we were mostly interested in the steady state circulation, the ADCP current time series were first detided using the T_TIDE software (Pawlowicz et al., 2002$)$ to remove current fluctuations associated with the diurnal (primarily K1 and O1) and semi-diurnal (primarily M2 and S2) tides.

\section{Ocean bathymetry}

We used the regional bathymetry dataset designed by Mayet et al. (2013), they modified the Beaman et al. (2011) bathymetry under the MGT using information on the grounding line and iceberg drafts.

\subsection{Atmospheric forcing and sea ice data}

Daily air-sea fluxes were taken from the ERA-Interim (ERA-I) reanalysis (Dee et al., 2011) and a mean wind stress curl was derived over the Adélie Depression (Figure 3). Additionally, 10-minute surface 


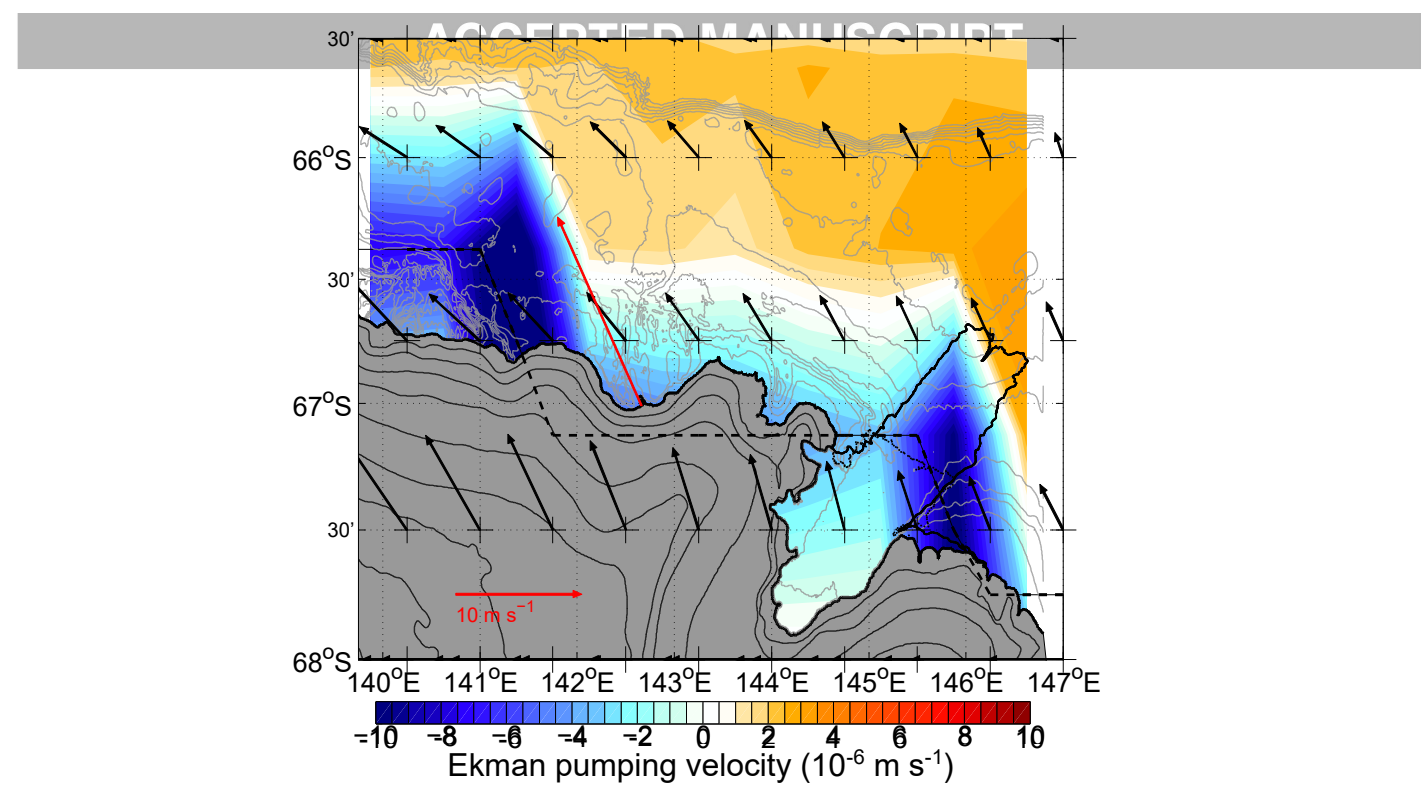

Figure 3: Mean surface wind velocity in January 2008 deduced from the ERA-Interim reanalysis (black arrows) and from the Cape Denison AWS observations (red arrows) superimposed onto the Ekman pumping velocity (in $10^{-6} m s^{-1}$ ) (filled countours). Red and blue shading indicates upward and downward Ekman velocities, respectively.

wisc.edu/aws/) were used to evaluate the validity of the ERA-I surface winds in the near-coast region. The net surface heat fluxes were calculated as the sum of the net shortwave and longwave radiations and the latent and sensible heat fluxes.

We used AMSR-E sea ice concentration (SIC) data which are routinely processed with the ASI algorithm and delivered at $6.25 \mathrm{~km}$ resolution by the Bremen University (Spreen et al. 2008 ). While the region was almost ice-free during the ALBION 2008 cruise, sea ice melt was at play in the preceding months. We used sea ice melt rates calculated over the melting period (October-February) by Lacarra et al. (2014) based on sea ice concentration and a fixed constant thickness for the sea ice.

The glacier draft data (Legrésy et al., 2004) were used to derive the under ice water column thickness. The mean glacier draft evaluated across the Adélie Depression from Buchanan Bay to the Mertz Bank (where the glacier tongue was grounded prior to its calving) was about 300-400 m (Lescarmontier, 2012 , Figure 2).

\section{Methods}

\subsection{Reconstruction of the water mass distribution}

Past definitions of the water masses on the shelf off AGVL (e.g. Williams and Bindoff, 2003, Lacarra et al. 2011) were based on definition intervals in the $\theta$-S space, including a neutral density $\gamma_{n}$ ) criterion (following Whitworth et al. 1998 ) to characterize the mCDW. Unfortunately, the $\gamma_{n}$ criterion is likely inaccurate in the AGVL region due to lack of data in the original $\gamma_{n}$ derivation dataset. To better constrain the water mass definition, using in addition information from the dissolved oxygen content, it was decided to use the optimal multi-parameter (OMP) analysis technique Tomczak, 1981: Budillon et al. 2003) to characterize the different water masses on the shelf. Details of the analysis can be found in Appendix B

An isotropic ordinary kriging method (Matheron, 1963, Journel and Huijbregts, 1978) was employed to reconstruct the horizontal distributions of different parameters characterizing the water masses. A decorrelation radius was obtained for each parameter to be mapped based on individual experimental variograms (not shown) fitted to an exponential function. For all parameters this scale in the intermediate layer was in the range $37-55 \mathrm{~km}$ and roughly corresponded to the higher bound of the CTD cast spacing. It is therefore possible that our hydrographic array missed relevant subgrid scale hydrographic features. 


\subsection{Inverse model to estimate the geostrophic velocity ANUSCRIPT}

\subsubsection{Model design}

Geostrophic shear velocities have been calculated using the thermal wind relation applied to successive station pairs along hydrographic sections. In order to estimate the velocity shear at station pairs located over sloping bottom, the specific volume gradient distribution must be estimated in the layer extending from the bottom level of the shallower station (the deepest common level, DCL) to that of the deeper station of the pair. Following the method proposed by Jacobsen and Jensen (1926), the layer below the DCL is divided by a straight line linking the bottom level of the two stations and separating two triangular subdomains, the upper one in which the specific volume is assumed to vary linearly in the $\mathrm{x}$ and $\mathrm{z}$ directions and a lower one in which the water is assumed motionless with zero horizontal density gradient. The absolute geostrophic velocity perpendicular to a given section is then defined as :

$$
V_{n}(x, z)=v_{s}(x, z)+b(x),
$$

205 velocity. In order to estimate the absolute geostrophic velocity, the reference velocity must be known. In the absence of direct velocity measurements, an indirect estimate of this velocity must be used. We use the steady geostrophic box inverse model described by Wunsch (1996) in which conservation of mass, salt and heat are imposed (within realistic uncertainties) on specified control volumes. The control volumes are bounded in the horizontal by a closed hydrographic sections either extending from the surface to the bottom or bounded in the vertical by prescribed isopycnal surfaces. Diapycnal fluxes are included explicitly in the constraints, which leads to additional unknowns to the problem. The conservation constraints being applied simultaneously to several layers/tracers, after discretizing the tracer fluxes across the boundaries, a system of linear equations is solved for the model unknowns (see Appendix C.1 for more details). The number of constraints being usually smaller than the number of unknowns, we used the Gauss-Markov method which is adapted to find the best unbiased estimation of underdetermined systems of linear equations (see Wunsch, 2006).

\subsubsection{Model implementation}

\section{Model geometry}

The inverse model (described in section 3.2.1 and Appendix C) has been implemented using a subset of 50 CTD casts from the ALBION 2008 summer cruise as input data. The inversion was performed separately on three different control volumes, hereafter referred to as model boxes, each bounded by a closed CTD section, allowing for some volume overlapping between boxes (Figure 1). The three model boxes were defined in order to insure approximate synopticity of the observations (each box was completed within a time interval of 25-36 hours depending on the box), while encompassing a reasonable water volume to reduce uncertainties on conservation constraints. The Sill box (depth range 220-665 m), covering the outer shelf region, can be considered representative of the exchanges through the Adélie Sill. Its northern boundary will be hereafter referred to as the Sill section. The Depression box (depth range $220-786 \mathrm{~m}$ ) encompassed the northern part (directly upstream of the sill) and the central part of the Adélie Depression, while the Mertz box (depth range 294-1123 m) encompassed the southern, deepest part of the Adélie Depression with its southernmost boundary lying along the MGT some 10-20 km away from the tongue. The latter is referred to as the Mertz section. All three boxes were defined by two CTD subsections running roughly parallel across the depression and joined together by two side subsections. 235 Some of these side subsections (for the Sill box and the Depression box) were running along the shallows of the Mertz Bank (over bottom floor of ca. 300-400 m) and the Adélie Bank (over bottom floor of ca. $220-250 \mathrm{~m}$ ) or reached close to the entrance of Commonwealth Bay over depth of ca. $550 \mathrm{~m}$. However, for the Mertz box, the cross-depression subsections did not run far enough to reach the shallow parts of the coast and the box had to be closed in the deepest part of the depression in water depths of more than $1100 \mathrm{~m}$

For each box, the conservation constraints (Equation C.4) were formulated on three different model layers. The isopycnal surfaces which were chosen as model layer interfaces were selected based on considerations on the stratification and on the water mass distribution. In each of the three layers, the salinity appeared to be fairly uniform across the different model boxes while the temperature in the upper two layers was more contrasted between these boxes (Table C.5. 


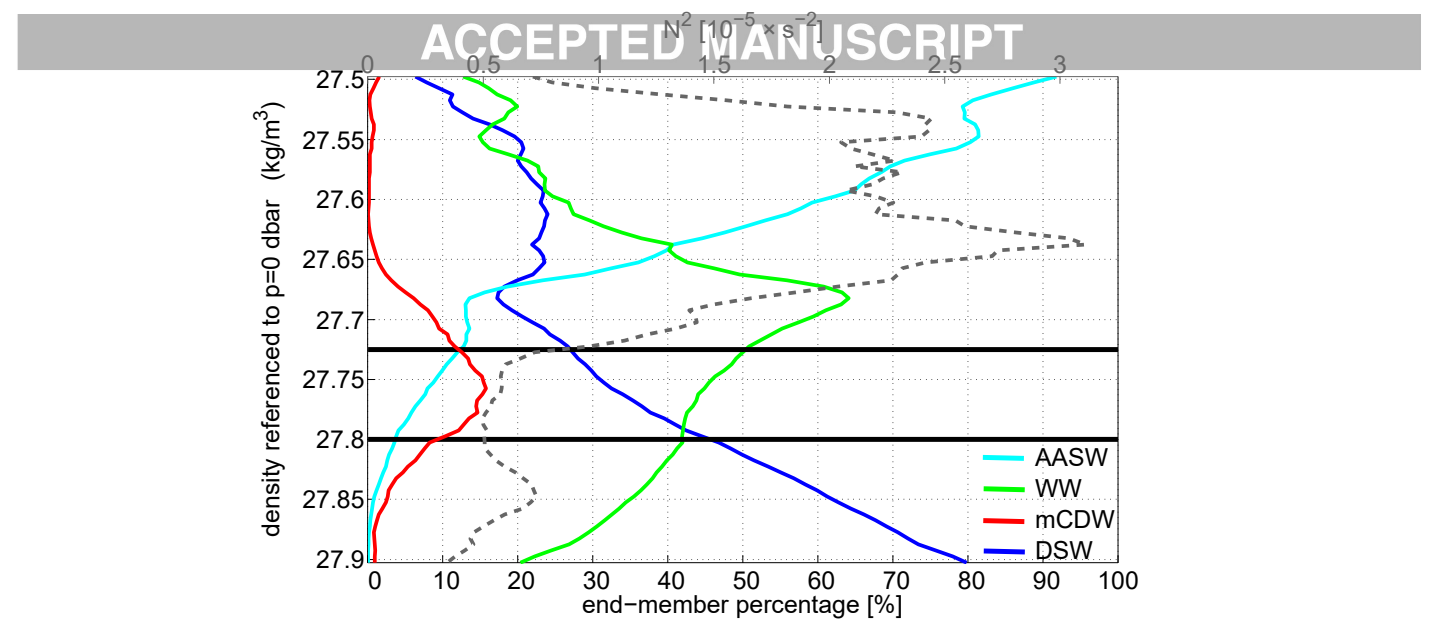

Figure 4: Mean percentage of each water mass end-member as a function of density (in $\sigma_{0}$ units) estimated from all ALBION 2008 CTD- $O_{2}$ casts for the Winter Water (green), the Antarctic Surface Water (cyan), the modified Circumpolar Deep Water (red) and the Dense Shelf Water (blue). Also shown is the mean stratification estimated over the entire model domain (grey dashed line). Box inverse model density surfaces (horizontal black lines).

Two isopycnal surfaces, $\sigma_{0}=27.725$ (mean depth $137-181 \mathrm{~m}$ ) and $\sigma_{0}=27.80$ (mean depth $316-330 \mathrm{~m}$ ) were selected as interfaces between the upper and intermediate layer, and between the intermediate and lower layer, respectively. As shown in Figure 4 , the $\sigma_{0}=27.725$ isopycnal was lying immediately below the upper, temperature- and salinity-stratified layer which concentrates most of the effects of the air-sea fluxes and encompassed the less diluted mode of AASW. This upper layer also included remnants of the winter surface mixed layer materialized by a core of WW lying at the base of the layer. The intermediate layer concentrated most of the mCDW, the latter mostly appearing in a highly diluted mode (maximum averaged concentration of less than $20 \%$ ), and was characterized by a local minimum of stratification. The $\sigma_{0}=27.80$ isopycnal which was chosen as the lower limit of this intermediate layer was lying immediately above the strong halocline capping the DSW reservoir which constituted the deeper layer.

\section{First guess on model unknowns : mean and uncertainty}

When using linear inverse modelling, it is usually assumed that the estimate of the unknown reference level velocity should arise as a small correction to a prescribed first guess value. The observations at MG suggest that it is reasonable to assume small reference velocities near the bottom. However, lacking information over the rest of the Adélie Depression, we had to assume that these velocities were small all over the depression, and small enough that a null velocity can be chosen as a first guess. This choice is in agreement with the weak bottom flow found in summer in numerical model simulations of this region (Kusahara et al. 2011). In absence of a-priori information on the spatial distribution of the velocity at any particular level we chose to put the a-priori level of no motion of a given station pair at the DCL between the two stations to allow for possible counter-flow as was indeed observed in the near bottom layer at MG. Doing so, we also avoid propagating the uncertainty on the flow reconstructed below the DCL towards the full velocity profile above (Ganachaud, 2003). Similarly, we assumed as first guess that diapycnal exchanges of mass and tracers were negligible (for a discussion, the reader is referred to Appendix C.2

The Gauss-Markov approach requires estimating a-priori uncertainty on the model unknowns. We examine current velocity observations at the mooring MG in order to provide a realistic first guess for the problem unknowns (see section 4.1). For the reference velocity, the latter can be obtained by taking the magnitude of the along-slope velocities observed at the bottom (second ADCP bin from the bottom) at MG in summer, which was $1.510^{-2} \mathrm{~m} \mathrm{~s}^{-1}$. The a-priori uncertainty on the diapycnal velocities was determined so as to guarrantee that diapycnal exchanges play a minor role relative to the horizontal dynamics in the minimization (see Appendix C.2).

\section{Conservation constraints}

Conservation constraints were applied simultaneously on the three layers previously introduced. Mass conservation was applied on each layer as well as on the total volume (the latter constraint being inde- 
pendent on uncertainties on the diapycnal fluxes). Given the large uncertainties on the air-sea heat and fresh water fluxes, and anticipating that a large part of these fluxes might have been accommodated by concomitant tendencies in the heat and fresh water contents of the upper layer, both being associated with as large uncertainties, it was decided to waive the heat and salt conservation constraints in the upper layer for all the three boxes and only require heat and salt conservation in the other two layers. Additionally, for the upper layer mass conservation constraint, a source term was added to the geostrophic flow convergence in the form of an Ekman transport convergence.

In the Gauss-Markov framework used to solve the model equations, explicit account of the noise on the observations leads to an uncertainty on the a-priori estimate of the constraints. The uncertainty is assumed to be a random variable with null mean and a covariance matrix $R_{n n}$. There are several noise sources in an inverse box model (see Ganachaud 2003, for a review). Details about the estimation of the associated error in the inverse box model are provided in Appendix D. All sources of errors were assumed independent of each other and individual noise variances were therefore added altogether to give an estimate of the total error on the constraints.

\section{Results}

\subsection{Observed current velocity structure and seasonality from mooring observations}

ADCP observations at mooring MG provide useful information on the current structure and variability in a deep layer extending from the bottom (ca. $900 \mathrm{~m}$ ) to roughly $500 \mathrm{~m}$ depth. These observations allow us to evaluate the relevance of the steady geostrophic assumption and box inverse modelling on the shelf and to obtain an order of magnitude for the reference level velocities to be retrieved from the inverse model. In both 2008 and 2009, the low-pass filtered (1 month) kinetic energy of current showed a strong

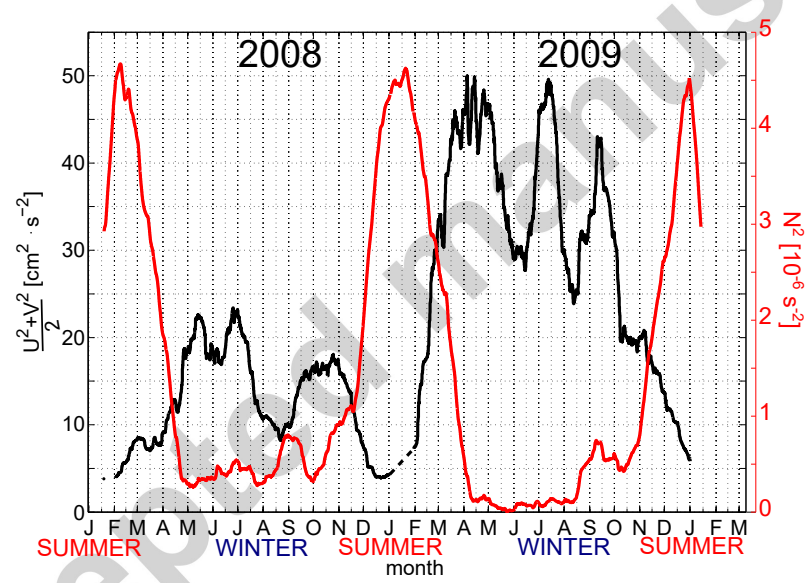

Figure 5: Bottom kinetic energy estimated from the velocities recorded by the ADCP and averaged in the lower $300 \mathrm{~m}$ of the water column (in $\mathrm{cm}^{2} \mathrm{~s}^{-2}$ ) (black line), and vertical mean of the squared Brunt-Väisälä frequency estimated between the two shallower microcats (in $s^{-2}$ ) (red line) in 2008 and 2009 at the MG mooring. The depths of the microcats are 278 $\mathrm{m}(237 \mathrm{~m})$ and $594 \mathrm{~m}(546 \mathrm{~m})$ in 2008 (2009), see Table 1

seasonal cycle at all levels, with an annual minimum reached in summer and followed by an abrupt increase in February (note however that this particular period of the year was not perfectly resolved as it corresponds to the time of mooring servicing) prior to reaching a maximum throughout the fall-winter period (the latter associated with large low-frequency variability). The annual cycle was observed down with concomitant changes in the deep stratification (Figure 5). The squared Brunt-Väisälä frequency, $N^{2}\left(N^{2}=-\frac{g}{\rho} \frac{\partial \rho}{\partial z}\right)$, averaged in the layer extending between the two shallowest microcats of the mooring (roughly between $261 \mathrm{~m}$ and $577 \mathrm{dbar}$, see Table 1) showed a strong seasonal cycle roughly in opposite phase to the KE cycle. The $N^{2}$ evolution highlighted a period of weak stratification in fall-winter $\left(N^{2}\right.$ values as low as $10^{-6} \mathrm{~s}^{-2}$ were found in May 2009 and $\mathrm{KE}$ is higher than $20 \mathrm{~cm}^{2} \mathrm{~s}^{-2}$ in 2008 and 45 $\mathrm{cm}^{2} \mathrm{~s}^{-2}$ in 2009 which respectively correspond to velocities of 6.3 and $9.5 \mathrm{~cm} \mathrm{~s}^{-1}$ ). This period was 
followed by a period of progressive restratification occurring between mid-August and early January in both years. This evolution suggests that December-January, which includes the time of our hydrographic surveys, corresponds to the most stratified (for the intermediate levels) and least energetic (for the deep wer column) period of the year, KE is about $5 \mathrm{~cm}^{2} \mathrm{~s}^{-2}$ which corresponds to a velocity of $3.2 \mathrm{~cm} \mathrm{~s}^{-1}$ This period of the annual minimum of KE will be hereafter referred to as the summer period. Note that, since the MG mooring was first deployed in mid-January 2008, the period of averaging is reduced in this particular year.

The seasonal evolution of the bottom KE shown in Figure 5 was likely related to the seasonal deepening of the core of the current during the destratification phase and its removal during the restratification phase. Current velocities recorded during the winter period (July-August-September) in 2008 and 2009 revealed a vertical structure characterized by a predominantly along-slope (southeastward) current heading to the MGT throughout the entire water column. Along-slope velocities reached almost $5 \mathrm{~cm} \mathrm{~s}^{-1}$ in the near bottom layer (Figure 6a). In summer, in January-February, strong baroclinicity of the current

(a)

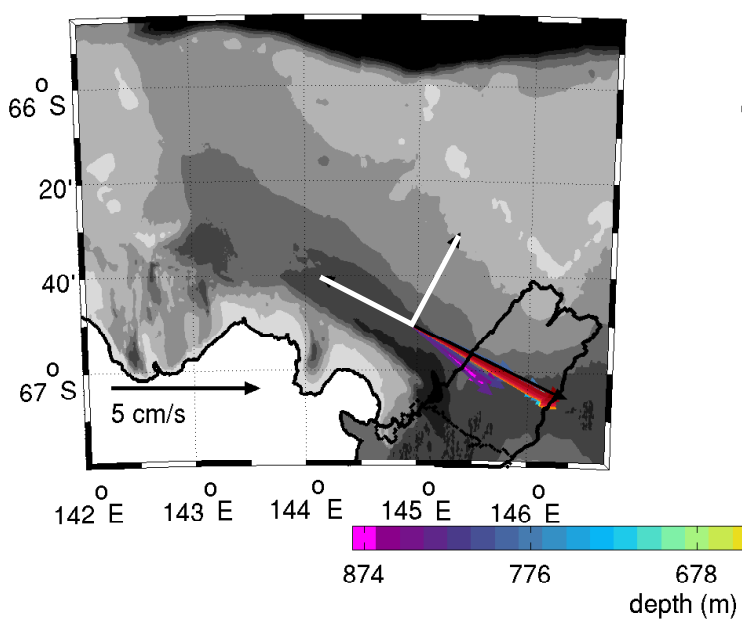

(b)

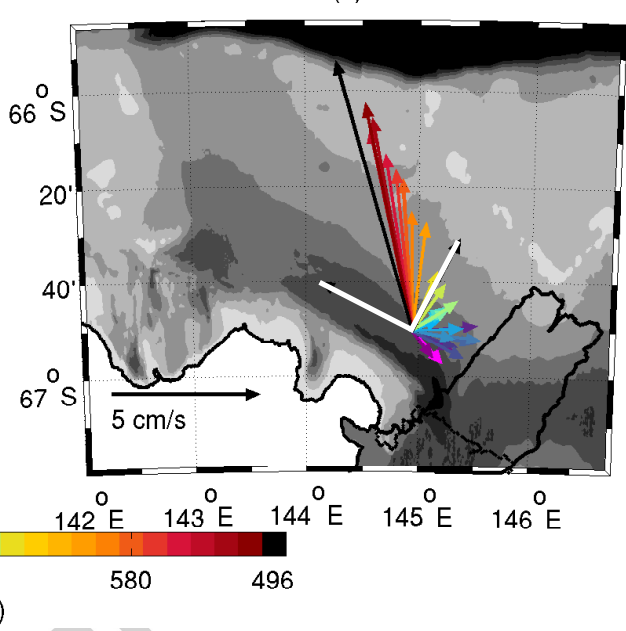

Figure 6: Current velocity at the MG mooring in (a) winter (May-September) and (b) summer (January 19-February 10) 2008. Arrows are colored according to depth. The white arrows represent the along- and cross-slope directions at the mooring location.

contrasted with the strong barotropic component of the current observed in winter (Figure 6b). The current was characterized by a marked anticlockwise upward veering of the current, having a mean alongslope southeastward component (directed toward the MGT) close to the bottom, then turning within a $220 \mathrm{~m}$ depth range to a dominant on-slope component at $700 \mathrm{~m}$, and ultimately to a dominant northnorthwestward heading at $500 \mathrm{~m}$ (directed toward the sill). The magnitude of the current also increased upward with speed reaching almost $10 \mathrm{~cm} \mathrm{~s}^{-1}$ at $500 \mathrm{~m}$ while being on the order of $1 \mathrm{~cm} \mathrm{~s}^{-1}$ at the bottom. A similar picture was retrieved in the summer 2009 (not shown), yet current speeds at $500 \mathrm{~m}$ did not reach beyond $5 \mathrm{~cm} \mathrm{~s}^{-1}$. The significant upslope component of the flow above $700 \mathrm{~m}$ would be consistent with an along-slope increase of the mean water column density when closer to the MGT. In the $220 \mathrm{~m}$ thick bottom layer, the upslope flow remained very small suggesting that a level of no motion did exist at some distance from the bottom (see also Figure 7). The bottom velocity averaged over this bottom layer was fairly small, amounting to $1.6 \pm 1.2 \mathrm{~cm} \mathrm{~s}^{-1}$ and $0.9 \pm 2.5 \mathrm{~cm} \mathrm{~s}^{-1}$, in 2008 and 2009, respectively. The mean summer shear at MG was compared with the geostrophic shear evaluated from a CTD station pair in the vicinity of the mooring. As the CTD sections were primarily aligned with the cross-slope direction (Figure 1), the geostrophic shear can be assumed to represent roughly the alongslope component of the flow. Without a-priori knowledge of a reference velocity, the geostrophic velocity was calculated relative to the DCL of the two stations, allowing for non-zero velocities at the bottom. Comparing the shape of the along-slope velocity shear, reasonable correspondence was found between the ADCP measurements and the geostrophic estimate (Figure 7). In particular, both velocity profiles showed an intensification of the current at the intermediate level $(300-500 \mathrm{~m}$ ) (although the maximum was found slightly farther up in the geostrophic estimate, perhaps due to the CTD station pair lying higher up on the slope relative to the mooring) and a rapid decrease of the along-slope velocity when approaching the bottom. As will be discussed in section 4.2.1, the baroclinic structure of the flow which 


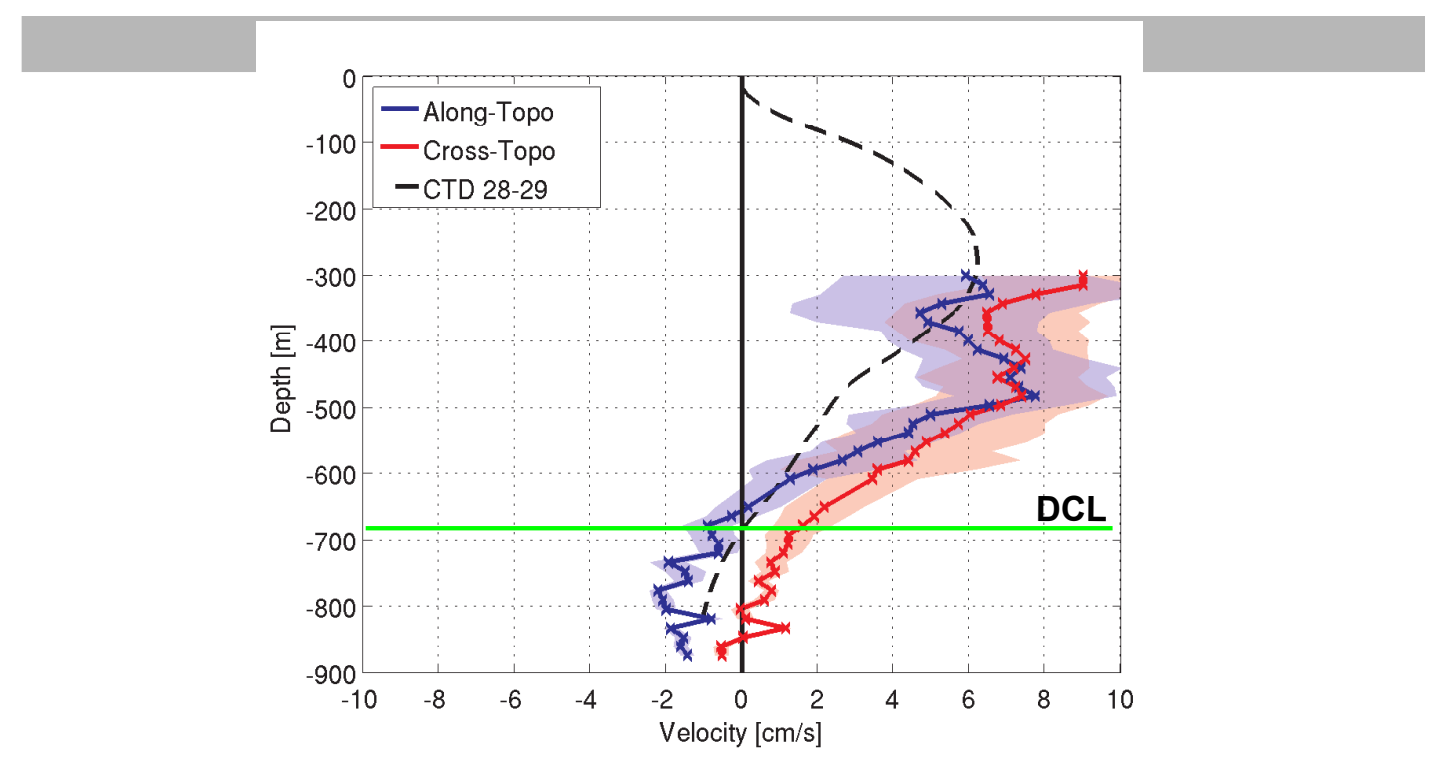

Figure 7: Along-slope geostrophic shear velocity estimated on January 15, 2008 from the nearest station pair relative to the MG mooring (dashed black line) and mean along-slope (blue) and cross-slope (red) components of the velocity measured at the MG mooring in summer 2008 (January 19-February 10), with their respective 95\% confidence interval (color shading). The DCL of the station pair is shown as a green line. The position of the station pair is shown in Figure 1

was observed in the deep layer at the MG mooring characterized more widely the geostrophic current deduced from the hydrographic observations in the Adélie Depression.

To summarize, the substantial baroclinicity of the flow observed in summer 2008, the reasonable agreement between the measured velocity shear at the MG mooring and its geostrophic estimate and the existence of a relatively weak bottom flow (despite sloping bottom floor at the mooring would suggest enhanced bottom flow there) are all arguments suggesting that inverse modeling could be a relevant tool to estimate the summer circulation in the Adélie Depression.

\subsection{The geostrophic circulation in summer 2008}

In this section, results from the inverse model are presented for a control case using the set of parameters described in 3.2 .2 . We focus on the circulation and the water mass transports on the shelf as well as the associated tracer fluxes.

\subsubsection{Reconstruction of the summer circulation and volume transports using the inverse model}

\section{Evaluation of the conservation constraints}

The magnitude of the residuals relative to the a-priori error on the constraints is a measure of the expected impact of these constraints on the inverse model solution.

Initial (prior-to-inversion) residuals on the constraints have same order of magnitude as the a-priori error on these constraints and, consequently the system is weakly constrained. In the upper layer, Ekman suction velocities were in the range 1.2-2.1 $10^{-6} \mathrm{~m} \mathrm{~s}^{-1}$, depending on the model box, or, for an Adélie Depression area of roughly $10^{4} \mathrm{~km}^{2}$, were equivalent to a lateral mass flux convergence of $\mathrm{O}\left(10^{-3} S v\right)$ which appears to be negligible in view of the $\mathrm{O}\left(10^{-1} S v\right)$ error on the upper layer geostrophic mass flux convergence. Disregarding the near coastal region where the wind stress is poorly estimated by the ERA-I reanalysis, the wind stress curl averaged over the Adélie Depression was indeed small in January 2008 (Figure 3). Despite atmospheric reanalyses are known to underestimate the surface winds in both winter and summer in Antarctic coastal areas (yet with better performance of the ERA-I reanalysis compared with the ERA-40 reanalysis, Rodrigo et al. 2013), it is reasonable to conclude that, in summer 2008, the surface Ekman flow contributed very little to the overall mass budget of the region.

As expected, after inversion, the residuals on the constraints are zero within the uncertainties in all layers in which constraints were applied. Furthermore, uncertainties on the diapycnal velocities and effective diffusivities quantities were always larger than the mean, so that diapycnal mass and tracer 
exchanges were not significantly different-from zero.v This result was expected considering that the apriori uncertainty on these unknowns was chosen so that correction to the horizontal dynamics was prioritized by the model solution over diapycnal processes. Consequently, we omit to comment these

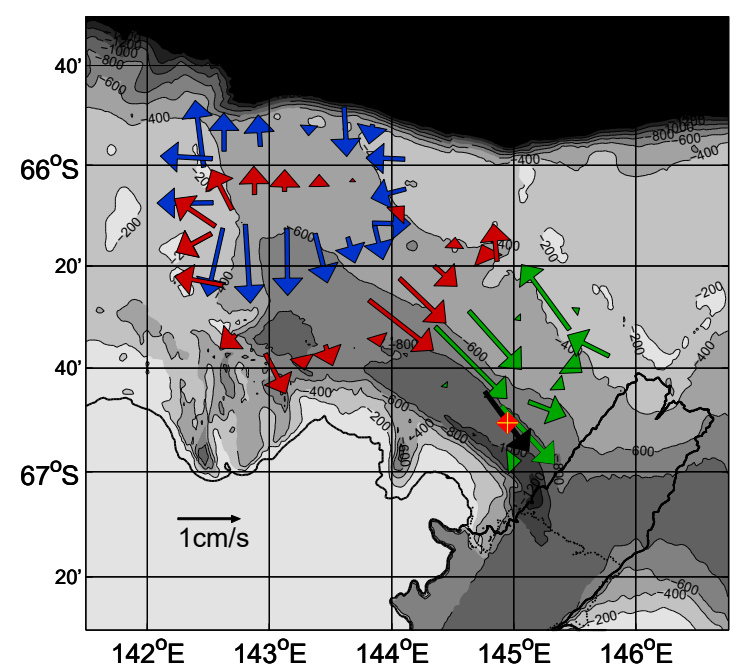

Figure 8: Cross-section bottom velocities after inversion (see explanation in text). The black arrow at the mooring location is the near-bottom summer velocity recorded by the ADCP and averaged between January 19 and February $10,2008$.

\section{Bottom flow}

Cross-section bottom velocities after the inversion are plotted in Figure 8 . For each station pair, these velocities were estimated midway between the DCL and the bottom of the deeper station. Consistently with the large residuals found in the lower layers of the Sill and Depression boxes, correction on the bottom velocities were larger in the vicinity of the sill $\left(0.2-1.3 \mathrm{~cm} \mathrm{~s}^{-1}\right)$. Yet, bottom velocities were the strongest near the western and southern corners of the Mertz box in the 500-850 m isobaths range (maximum velocities on the order of $1.6 \mathrm{~cm} \mathrm{~s}^{-1}$ ) where bottom currents flowed from the sill toward the MGT. The magnitude of the bottom flow calculated at the closest station pair to the mooring MG $\left(1.3 \pm 1 \mathrm{~cm} \mathrm{~s}^{-1}\right)$ was very similar to the along-slope bottom velocity recorded by the ADCP over the period of minimum bottom kinetic energy (black arrow in Figure 8, see section 4.1).

In the sill region on-shelf bottom velocities were found limited to the northeastern part of the sill. Yet the flow might not have penetrated farther south but rather contributed to the northward recirculation observed in the northwestern part of the sill. At the south of the sill, the inflow to the inner depression which occurred was much larger than the inflow at the north of the sill suggesting a diverging bottom flow fed by vertical advection or mixing. This information would be consistent with the negligible bottom velocities found in the interior sill region (as found on the northern section of the Depression box), which do not suggest a continuous horizontal southward bottom flow over the sill.

Gyre circulation and integrated volume transports

An overall view of the spatial distribution of the currents can be obtained by examining different vertical sections across the Adélie Depression between the sill and the Mertz region (Figure 9 a-f). As the sections were running roughly aligned with the bottom topography gradient, they captured the essentials of the along-slope flow. The bottom flow was everywhere small compared with the magnitude of the baroclinic shear. On all sections the flow appeared to be mainly concentrated above the $\sigma_{0}=27.80$ isopycnal roughly corresponding to the upper boundary of the DSW. The current have a strong barotropic component with surface (or subsurface) intensified velocities and only occasional (like, e.g., in the vicinity of the MG mooring) reversal of the flow in the near bottom layer. Considering the succession of cross sections, a coherent structure of the flow is identified in the upper 300-400 m. The flow was organized into a southeastward inflowing branch over the upper southwestern flank of the Mertz Bank (roughly above the 300-400 m isobaths) and a northwestward outflowing branch centered over the northeastern slope of the Adélie Depression and progressively displaced toward the central depression and over the western sill at it approached the outer shelf. Core velocities (on the order of 10-20 $\mathrm{cm} \mathrm{s}^{-1}$ ) were found closer 

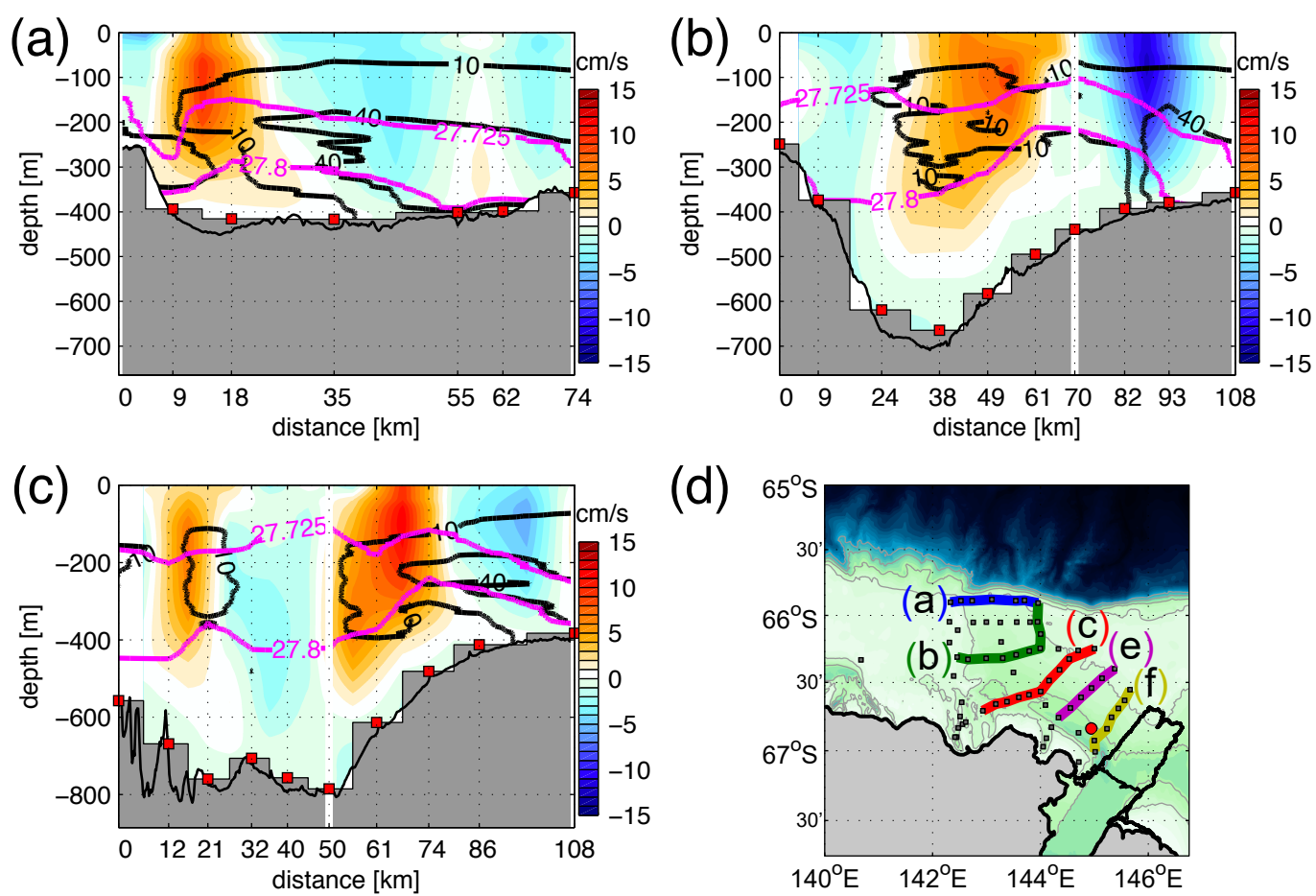

(d)
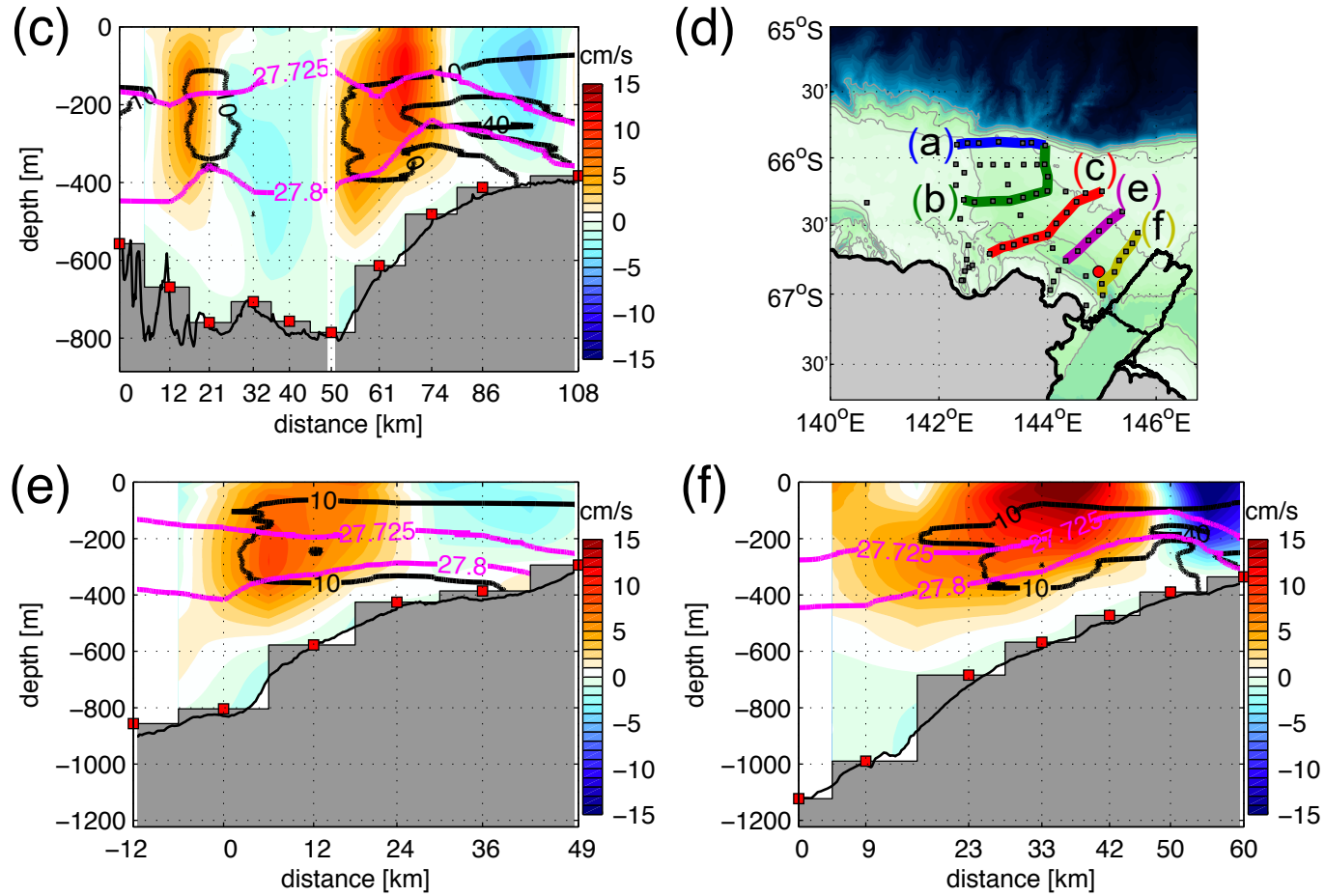

Figure 9: Cross-section geostrophic velocities (in $\mathrm{cm} \mathrm{s}^{-1}$ ) after inversion for (a)-(b) the northern and southern Sill box sections, (c) the southern Depression box section and (e)-(f) the northern and southern Mertz box sections. Also shown are isopleths of the mCDW end-member concentration (black contours) and the 27.725 and 27.8 isopycnals used as model interfaces (magenta contours). Northward (resp. southward) velocities are shown in red (resp. blue). A map showing the location of each section is shown in (d): northern (blue) and southern (green) Sill box sections, southern Depression box (red), northern (magenta) and southern (yellow) Mertz box sections.

to the surface in the inflow branch than the outflow branch where a subsurface velocity maximum was identified between $100 \mathrm{~m}$ and $400 \mathrm{~m}$ depending on the section. Only on the southernmost section near the MGT did the outflow branch appear as a surface-intensified flow with enhanced baroclinic shear in the upper layer. Our results therefore suggest differing characteristics for the two branches. While the inflow branch was clearly surface-intensified with $71 \%$ of its transport occurring in the upper layer, the outflow branch reached deeper with $83 \%$ of its transport almost equally distributed between the upper and intermediate layer. The inflow and outflow branches were located on either side of the DSW dome, the latter culminating over the upper slope of the Mertz Bank (over the $400-500 \mathrm{~m}$ isobaths) except at the northern sill where it was displaced toward the Adélie Bank. This feature suggests that the DSW dome acted as a dynamic guide for the upper layer circulation.

To the first order, the vertically integrated flow on the shelf resembles a clockwise gyre circulation which communicate with the offshore by an inflow and an outflow in the eastern and western sill, respectively (Figure 10a). The gyre circulation was about $0.34 \pm 0.13 \mathrm{~Sv}$ and $0.64 \pm 0.36 \mathrm{~Sv}$ (the \pm sign is for the standard deviation calculated over the different cross-gyre sections) for the transports in the inflow and outflow branch, respectively. However, the variability of the transports along the depression 
was high and some exchanges could exist-between the inner depression and the neighbouring regions to the east and west of the gyre. Net inflows to the depression of $0.13 \pm 0.13 \mathrm{~Sv}$ and $0.95 \pm 0.19 \mathrm{~Sv}$ were diagnosed through the Sill section and Mertz section, respectively. While the net inflow at the sill was

430 within the error bar, the large northwestward flow entering the depression from the southeastern part of the domain through the Mertz section was certainly a real feature (which will be discussed in the next section) contributing to make the returning northwestward branch of the gyre circulation almost twice as large as the southeastward branch. Progressively decreasing strength of the outflow branch as it flows from the MGT toward the sill further suggests possible local recirculations.

\begin{tabular}{|c|c|c|c|c|c|c|c|c|c|c|}
\hline & \multicolumn{3}{|c|}{ Inflow } & \multicolumn{3}{|c|}{ Outflow } & \multicolumn{3}{|c|}{ Net } \\
\hline & & Volume (V) & Heat $(\mathrm{H})$ & Freshwater $(\mathrm{Fw})$ & $\mathrm{V}$ & $\mathrm{H}$ & $\mathrm{Fw}$ & $\mathrm{V}$ & $\mathrm{H}$ & $\mathrm{Fw}$ \\
\hline \multirow{8}{*}{ Sill section } & Layer 1 & 0.233 & 256 & 1.06 & 0.099 & 62 & 0.14 & 0.134 & 194 & 0.92 \\
\hline & & \pm 0.053 & \pm 60 & \pm 0.23 & \pm 0.05 & \pm 81 & \pm 0.19 & \pm 0.07 & \pm 93 & \pm 0.28 \\
\hline & Layer 2 & 0.084 & 201 & -0.06 & 0.07 & -4 & -0.02 & 0.014 & 205 & -0.04 \\
\hline & & \pm 0.031 & \pm 97 & \pm 0.04 & \pm 0.031 & \pm 15 & \pm 0.01 & \pm 0.040 & \pm 96 & \pm 0.04 \\
\hline & Layer 3 & 0.018 & 1 & -0.05 & -0.018 & -46 & -0.01 & -0.023 & 48 & 0.04 \\
\hline & & \pm 0.011 & \pm 6 & \pm 0.04 & \pm 0.011 & \pm 29 & \pm 0.07 & \pm 0.026 & \pm 30 & \pm 0.07 \\
\hline & Total & 0.334 & 458 & 0.95 & 0.21 & 12 & 0.02 & 0.125 & 446 & 0.93 \\
\hline & & \pm 0.091 & \pm 156 & \pm 0.17 & \pm 0.106 & \pm 64 & \pm 0.13 & \pm 0.128 & \pm 158 & \pm 0.20 \\
\hline \multirow{8}{*}{ Mertz section } & Layer 1 & 0.224 & 361 & 1.36 & 0.729 & 607 & 3.53 & 0.505 & 246 & 2.17 \\
\hline & & \pm 0.028 & \pm 38 & \pm 0.15 & \pm 0.054 & \pm 46 & \pm 0.25 & \pm 0.058 & \pm 54 & \pm 0.27 \\
\hline & Layer 2 & 0.083 & 88 & -0.02 & 0.381 & -139 & 0.09 & 0.299 & -228 & 0.11 \\
\hline & & \pm 0.018 & \pm 23 & \pm 0.01 & \pm 0.036 & \pm 43 & \pm 0.02 & \pm 0.038 & \pm 48 & \pm 0.02 \\
\hline & Layer 3 & 0.033 & -40 & -0.09 & 0.178 & -213 & -0.48 & 0.145 & -173 & -0.39 \\
\hline & & \pm 0.020 & \pm 27 & \pm 0.07 & \pm 0.097 & \pm 162 & \pm 0.43 & \pm 0.097 & \pm 162 & \pm 0.43 \\
\hline & Total & 0.34 & 410 & 1.25 & 1.289 & 255 & 3.14 & 0.949 & -154 & 1.89 \\
\hline & & \pm 0.066 & \pm 34 & \pm 0.07 & \pm 0.186 & \pm 179 & \pm 0.21 & \pm 0.190 & \pm 183 & \pm 0.23 \\
\hline
\end{tabular}

Table 2: Volume $(\mathrm{Sv})$, heat $(\mathrm{GW})$ (relative to $\theta_{\text {ref }}=-1.52^{\circ} \mathrm{C}$ ) and freshwater $(\mathrm{mSv})$ (relative to $\left.S_{r e f}=34.49\right)$ transports across the Sill and Mertz sections (see Section locations in Figure 1.

The different magnitudes of the in- and outflow branch through the Mertz section (Table 2 and Figure 10a) suggest that most of the water supplied to the outflow branch should have entered the depression between this section and the MGT. Table22indicates that most of the water was supplied within the upper two layers where the southward flow was blocked by the immerged part of the MGT. We therefore suppose that part of the net mass transport imbalance through the Mertz section in these layers $(0.80 \mathrm{~Sv})$ was fed by a southward inflow from the Mertz Bank taking place near the tip of the MGT and recirculating in front of the glacier as part of the gyre circulation. In the lower layer, the net northwestward flow of 0.15 $\mathrm{Sv}$ from the MGT region to the inner depression was likely due to dense water flowing from underneath the glacier.

\subsubsection{Water mass distribution and pathways}

445 By combining the velocities estimated from the inverse model and an OMP analysis applied to the hydrographic observations, it is possible to estimate the transports and transformations associated with each water mass on the shelf.

$m C D W$

In Figure 9 the mCDW distribution derived from the OMP analysis was superimposed to the velocity distributions to identify the main $\mathrm{mCDW}$ pathways. On all sections the intermediate layer of the inverse model appeared dominated by the presence of $\mathrm{mCDW}$, with local maxima of mCDW relative concentrations roughly located within the velocity cores of the inflow (South-Eastward) and outflow (North-Eastward) branches. In the summer 2008, the mCDW entered the shelf in the northeastern part of the sill and, from there, turned eastward towards the Mertz Bank and continued its way southeastward following the upper flank of the Mertz Bank up to the MGT. After recirculating in front of the glacier the water mass entered the outflow branch of the gyre circulation flowing toward the Adélie Sill.

Transports associated with the more diluted mode of mCDW (water containing between $10 \%$ and $40 \%$ of the mCDW end-member, Figure 10d) were much larger than those associated with the less diluted mode 




(a)

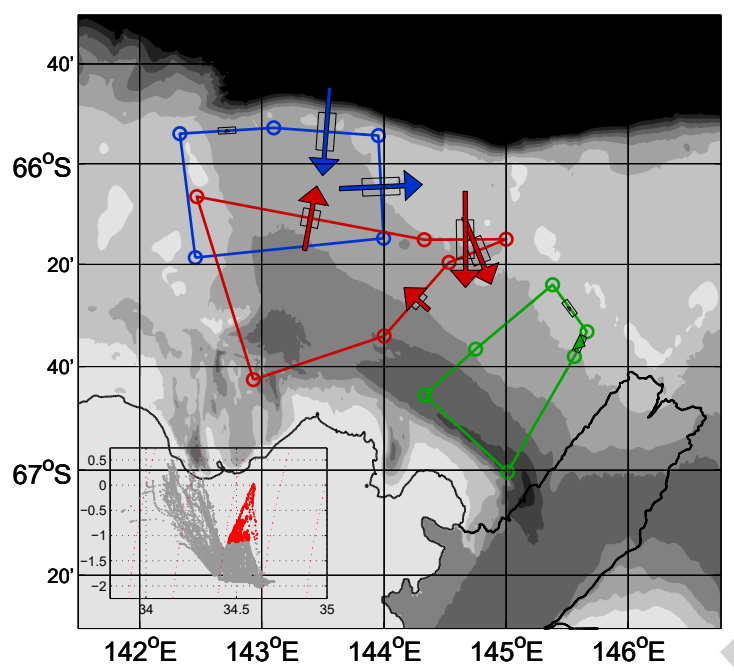

(c)

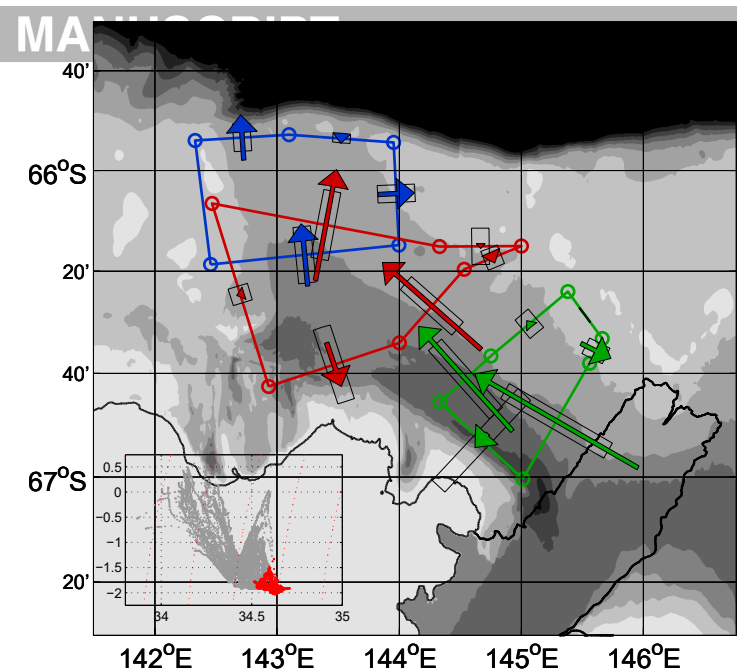

(b)

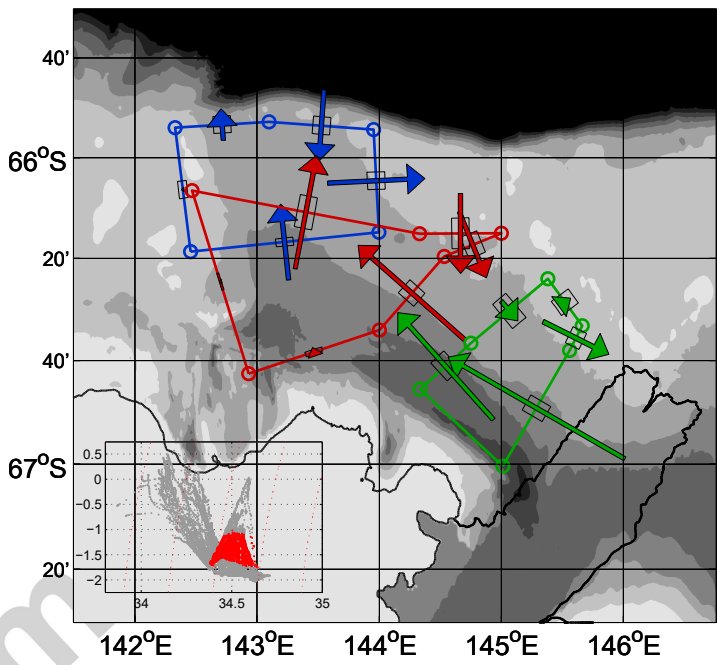

(d)

Figure 10: (a) Vertically integrated transport deduced from the inverse model. (b) Transport of the DSW modes containing at least $50 \%$ of the DSW end-member. (c) Transport of the mCDW modes containing at least $40 \%$ of the mCDW endmember. (d) Transport of the mCDW modes containing between $10 \%$ and $40 \%$ of the mCDW end-member. In (b)-(d) the insert shows at $\theta$-S plot of the corresponding modes (red) superimposed on the $\theta$-S characteristics of all CTD casts (grey). Inflow and outflow transports are estimated through model box sub-sections delimited by the white filled circles.

\begin{tabular}{clccc}
\hline & & Inflow & Outflow & Net \\
\hline & mCDW end-member & $0.071 \pm 0.026$ & $0.016 \pm 0.010$ & $0.055 \pm 0.026$ \\
Sill section & mCDW (10-40\%) & $0.114 \pm 0.028$ & $0.050 \pm 0.027$ & $0.065 \pm 0.035$ \\
& mCDW (40-100\%) & $0.071 \pm 0.030$ & $0.002 \pm 0.005$ & $0.069 \pm 0.030$ \\
& DSW end-member & $0.034 \pm 0.013$ & $0.079 \pm 0.033$ & $0.044 \pm 0.032$ \\
& DSW (50-100\%) & $0.008 \pm 0.007$ & $0.036 \pm 0.022$ & $-0.029 \pm 0.023$ \\
\hline \multirow{3}{*}{ Mertz section } & mCDW end-member & $0.037 \pm 0.008$ & $0.076 \pm 0.009$ & $0.039 \pm 0.011$ \\
& mCDW (10-40\%) & $0.118 \pm 0.024$ & $0.325 \pm 0.037$ & $0.207 \pm 0.040$ \\
& mCDW (40-100\%) & $0.008 \pm 0.004$ & $0 \pm 0$ & $-0.008 \pm 0.004$ \\
& DSW end-member & $0.061 \pm 0.021$ & $0.345 \pm 0.096$ & $284 \pm 0.096$ \\
& DSW (50-100\%) & $0.027 \pm 0.018$ & $0.150 \pm 0.095$ & $0.123 \pm 0.095$ \\
\hline
\end{tabular}

Table 3: Transports (in Sv) of the end-members and diluted mode of the mCDW and DSW through the Sill and Mertz sections. 
(water containing more than $40 \%$ of the mCDW end-member, Figure 10 ). Note that water masses which ${ }_{460}$ contained less than $10 \%$ of the mCDW end-member were considered too diluted to be counted as a mCDW mode. At the shelf break, almost two-thirds of the 0.19 Sv of mCDW inflowing through the northern sill section were mainly achieved by the more diluted mode (Table 3). The mCDW concentrations (defined as the percentages of mCDW end member) were lower in the outflow branch than in the inflow branch (especially at the sill section), and higher in the sill region than in the inner depression. Figure 10p shows that the less diluted mode of mCDW entering the sill was not penetrating beyond the middle of the Adélie Depression and, for a large part, recirculated northwestward at about $66^{\circ} 30^{\prime} \mathrm{S}$. Very little of this mode seems to have fed the more diluted mode which was the only mCDW mode found farther south (Figure 10 c and d). While this mode was found to flow with the gyre circulation, substantial recirculation of the northwestward recirculating branch was detected within the Mertz box (Figure 10d). Additionally, as for the total transport (Figure 10a), the mCDW end-member transports (not shown) showed discontinuities along the inflow branch, mainly at $66^{\circ} 40^{\prime} \mathrm{S}$ at the Mertz tip and also possibly near $66^{\circ} 30^{\prime} \mathrm{S}$. To cancel the net imbalance of $0.039 \mathrm{~Sv}$ of $\mathrm{mCDW}$ end-member passing northwestward through the Mertz section would require an equivalent inflow of this end-member between the MGT and the section. Figure $10 \mathrm{~d}$ suggests that this inflow could have been almost entirely achieved by $0.21 \mathrm{~Sv}$ of diluted mCDW.

475 Upper water masses

The two upper water masses, the AASW and the WW, exhibit circulation schemes (not shown) roughly similar to that of the mCDW. Substantial net transports of these two water masses from the MGT into the Adélie Depression were found through the Mertz section. In particular, 0.6 Sv of AASW (AASW being counted as water containing more than $10 \%$ of AASW end-member) from the Mertz Bank could

480 have contributed to an inflow in front of the MGT. Both the AASW and the WW also likely participated to substantial exchanges (on the order of $0.2 \mathrm{~Sv}$ ) to the west, between the inner depression and the shallow coastal region or the Adélie Bank.

\section{Dense Shelf Water}

The transports associated with the densest $\left(\sigma_{0}>27.88\right)$ variety of DSW, which is susceptible to form the AABW, was found to be negligible (not shown). In particular, no significant export of this water could be detected through the Sill section which is coherent with the small volume of this DSW observed at the sill section. Although a large proportion of the volume of DSW end-member was found in DSW varieties having concentrations lower than $50 \%$, these more diluted varieties spread all over the water column and could hardly be interpreted as organized patterns of DSW. The DSW circulation was rather well represented by the distribution of varieties containing more than $50 \%$ of the DSW end member, the $50 \%$ concentration isopleth also coinciding approximately with the $\sigma_{0}=27.80$ isopycnal forming the upper boundary of the dense water reservoir in the Aélie Depression (also the upper boundary of the lower layer of the box inverse model). The circulation highlighted an outflow pattern linking the MGT to the sill which was fed by waters originating from below the MGT (Figure 10p). A net transport of $0.12 \mathrm{~Sv}$ of these less diluted DSW varieties was found to flow northward through the Mertz section. This result suggests that about $0.12 \mathrm{~Sv}$ of DSW were flowing from underneath the MGT. Less than one-third $(0.05 \mathrm{~Sv})$ of this transport was identified as ISW, the latter spreading along the MGT over the entire northeastern slope of the Adélie Depression (Figures 2 and 11). However, very little of the water outflowing from underneath the MGT reachs the shelf break. Only a negligible amount $(0.04 \mathrm{~Sv})$ of the mode with a DSW concentration higher than 50\%, managed to escape the shelf in the northwestern part of the sill, while three-fourth of the DSW end-member flowing from underneath the Mertz was found to recirculate before reaching the sill (Table 3).

\subsubsection{Heat and fresh water transports and budgets}

We here consider vertically integrated heat and fresh water transports calculated relative to reference temperature $\left(-1.52^{\circ} \mathrm{C}\right)$ and salinity $(34.39$, in practical salinity units) equal to the average values over the three model boxes. By using such reference values, the transports can be interpreted in terms of possible changes in the mean heat or fresh water content of the model domain. The transports roughly followed the same gyre pattern as the volume transports (Table 2). The main conduits for the heat and freshwater inflow and outflow at the shelf break however were found at different levels in the water column. A net inflow of $446 \pm 158 \mathrm{GW}$ and $0.93 \pm 0.20 \mathrm{mSv}$ of fresh water was taking place through the northern sill, almost entirely associated with the inflow branch. However, while the heat input in the inflow branch was 
almost entirely distributed between the upper layer and the warm $\mathrm{mCDW}$ in the intermediate layer, the fresh water input to the shelf was contributed almost exclusively by the upper layer. In this layer only small portions of the heat $(25 \%)$ and fresh water $(13 \%)$ inputs were recirculated northward at the sill,

515 suggesting that most of the imported heat and fresh water was stored or lost farther on the shelf, either through air sea exchanges or being exported through the lateral boundaries of the domain. At the Mertz section, the inflow branch was still carrying heat and freshwater southward in the upper layer which were likely recirculated northward in front of the MGT together with the warm, fresh upper waters originating from the Mertz Bank. Similarly, in the intermediate layer, the heat imported in the inflow branch was not observed to recirculate at the sill. Instead, an overall tendency to decreasing core temperature of the mCDW along its path toward the MGT suggests progressive mixing of this water mass with the ambient colder waters on the shelf. In contrast to the upper layer, the net heat and fresh water fluxes in the intermediate layer through the Mertz section suggest a potential interaction with the MGT. Since the return outflow branch through the section was not recirculating northward the amount of heat imported

${ }_{525}$ by the inflow branch while carrying northward a larger amount of fresh water, it must have been fed by an additional source of relatively cold and fresh water. The origin of this water will be discussed in section 5. Consistently with the volume transport, the northwestward heat and fresh water transports through the Mertz section in the lower layer suggest an outflow of cold, saline water, likely originating from underneath the MGT, with some $20 \%$ of recirculation through the section.

530 Since the inverse model did not require heat and fresh water conservation in the upper model layer, it is interesting to diagnose a-posteriori the heat and fresh water budgets of this layer to evaluate the degree of realism of the inverse model solution and to identify the primary contributions to these budgets. Large, significant heat transport divergences were diagnosed in the upper layers which, depending on the model box, were in the range 9-68 $\mathrm{W} \mathrm{m}^{-2}$ (relative to the mean layer temperature and translated into equivalent 535 surface flux based on the model box area). The Ekman flow made a significant (30\%) contribution to this divergence in the Mertz box. Diapycnal heat fluxes at the base of the surface layer were found negligible. The transport divergences however remained small compared with the atmospheric surface heat input $\left(212 \pm 25 \mathrm{~W} \mathrm{~m}^{-2}\right)$ estimated from the ERA-I reanalysis. This result suggests that the upper waters were subject to a warming trend at the time of our observations. Heat content changes estimated over the early

540 summer period between the CEAMARC cruise and the ALBION cruise suggest that substantial warming of the upper layer, in the range 104-126 $\pm 29 \mathrm{~W} \mathrm{~m}^{-2}$, did occur between the two cruises. Although these estimates should be taken with caution due to large uncertainties, they are in agreement with the inverse model solution.

Depending on the model box, fresh water transport convergences in the range 5.3-9.7 $\mathrm{mm}^{\text {day }}{ }^{-1}$ were ${ }_{545}$ diagnosed in the upper layer, with larger amplitude in the Sill and Mertz boxes. While the contribution of the Ekman transport to these convergences was very small in the Mertz box, it exceeded $60 \%$ of the total transport convergence in the Sill and Depression box thus suggesting that wind was more efficient in transporting the surface fresh water in the outer shelf region (diapycnal fluxes were again negligible). Sea

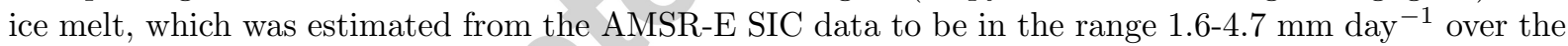

550 melting period (Lacarra et al. 2014), contributed additional fresh water input to the region. Considering that net evaporation from ERA-Interim $\left(0.46 \pm 0.31 \mathrm{~mm} \mathrm{day}^{-1}\right)$ was too small to compensate for any of these fresh water sources, freshening of the upper water column must have been at play during the ALBION cruise. Upper layer fresh water content changes estimated between the CEAMARC cruise and the ALBION cruise confirm this freshening trend, with values in the range 7.7-27.1 $\pm 4.7 \mathrm{~mm} \mathrm{day}^{-1}$. It

555 should however be kept in mind that these estimates are highly sensitive to the selected reference salinity.

\section{Discussion}

\subsection{Insight on the shelf dynamics based on the inverse model}

A circulation scheme for the AGVL shelf has been reconstructed based on hydrographic observations carried out in summer 2008 and an inverse geostrophic model. The scheme provides a comprehensive view of the summer circulation over the entire Adélie Depression and Adélie Sill domain while being consistent with mass, heat and salt conservation constraints in the limit of prescribed uncertainties. The analysis presented hereafter examines in more details the three-dimensional structure of the circulation and its relation to the density distribution and possible baroclinic and barotropic forcing mechanisms. Additionally, careful examination of the sources of model uncertainties (see Appendix D) allows us to 

in the earlier study of Snow et al. (2016).

Until recently, knowledge on the summer circulation on the AGVL shelf was only indirect, being based on either hydrographic property distributions (Lacarra et al., 2011$)$ or numerical model simulations (Kusahara et al. 2011). A recent study by Snow et al. (2016), based on a box model approach similar to the one used here, highlighted the presence of a fairly barotropic northwestward current over the central Adélie Depression which was suggested to be associated with coastal wind-driven downwelling. The summer circulation scheme proposed in this study is rather dominated by a gyre circulation which recirculates clockwise water entering the Adélie Depression through the Adélie Sill and additional pathways connecting the inner depression to the neighboring banks or to the deep depression underneath the MGT. Near the MGT, the transport associated with the northwestward branch $(0.95 \mathrm{~Sv} \pm 0.19 \mathrm{~Sv})$ which constitutes the return branch of the gyre circulation towards the Adélie Sill had same order of magnitude as the one associated with the coastal current proposed by Snow et al. (2016). Yet, we observed a larger southeastward flow over the upper slope of the Mertz Bank than these authors, which supports our hypothesis that this flow would be able to feed a gyre-like circulation over the depression. Consistently, while Snow et al. (2016) argue that the entire northeastward current flowing over the Adélie Depression should originate east of the MGT (after flowing underneath glacier tongue), we rather suggest that only the deeper part of this flow originated east of the MGT while, in agreement with potential vorticity conservation, the upper part would enter the depression from the Mertz Bank along the glacier tongue. Additionally, the gyre scenario is able to explain our observations of the water mass properties in 2008 , especially the presence of only weakly modified mCDW (compared to the mCDW in the southeastward branch) in the northwestward branch of the gyre, showing that the intermediate waters were not strongly interacting with the glacier as they should have if they had been flowing from underneath the glacier (not shown).

The circulation in the eastern Adélie Depression was found to have a strong baroclinic component. More specifically, our analysis of the geostrophic circulation suggests an impact of the deep stratification associated with the DSW distribution on the summer shelf circulation. Remembering that the DSW distribution is largely seasonal, being controlled by the history of winter homogenization and spring restratification, this result suggests strong seasonality of the shelf circulation in agreement with independent current measurements at our MG mooring (section 4.1) and earlier numerical model simulations (Kusahara et al. 2011) or box inverse modelling (Snow et al., 2016). Similar control on the seasonal evolution of the circulation by the thermohaline structure was also suggested in the western Ross Sea based on numerical model simulations (Assmann et al. 2003). In agreement with results of Kusahara et al. (2011) we find a surface intensified circulation organized along a clockwise cyclonic gyre around a dense water dome. However, several sets of observations collected in this region, including not only the present ALBION 2008 dataset but also the summer 2001 observations from the NBP00-08 cruise (Jacobs 2004) or the summer 2009 ALBION cruise (Lacarra et al., 2011), indicate that the geometry of the dome used to differ from the one found in these earlier simulations. While in the latter, the dense water dome appeared to be centered over the central, deepest part of the depression, the available observations rather suggest a marked asymmetry of the dome which was found to lie against, and to be aligned with, the northeastern slope of the depression. Consistently, in 2008, the gyre circulation was displaced above the flank of the Mertz Bank rather than organized along the isobaths surrounding the depression.

Examination of the vertical distribution of the stretching component of the Ertel potential vorticity (PV) $\left(q=-\frac{f N^{2}}{q}\right.$, where $f$ is the Coriolis parameter and $g$ the gravity acceleration), revealed that vortex stretching in the intermediate water column in the eastern Adélie Depression was largely determined by the topography of the dense water dome and the stratification immediately above (Figure 11). As a consequence, the reconstructed mCDW circulation in summer 2008 appeared to be largely constrained by conservation of this stretching component (Figure $12 \mathrm{a}$ ). In particular, above the dome, the mCDW layer tends to be squeezed, forcing the core of the water mass to flow against the flanks of the dense water dome. On the other hand, enhanced stretching in the upper part of the intermediate layer, due to rising e in seen from the geometry of the $\sigma_{0}=27.725$ isopycnal in Figure 11), adding another potential vorticity constraint on the mCDW flow. The inflow at the shelf break occurred mainly to the east of the Adélie Sill and turned southeastward as a current steered by the slope of the Mertz Bank. From there the current continued toward the MGT, flowing against the northeastern flank of the dense water dome. The deep stratification 


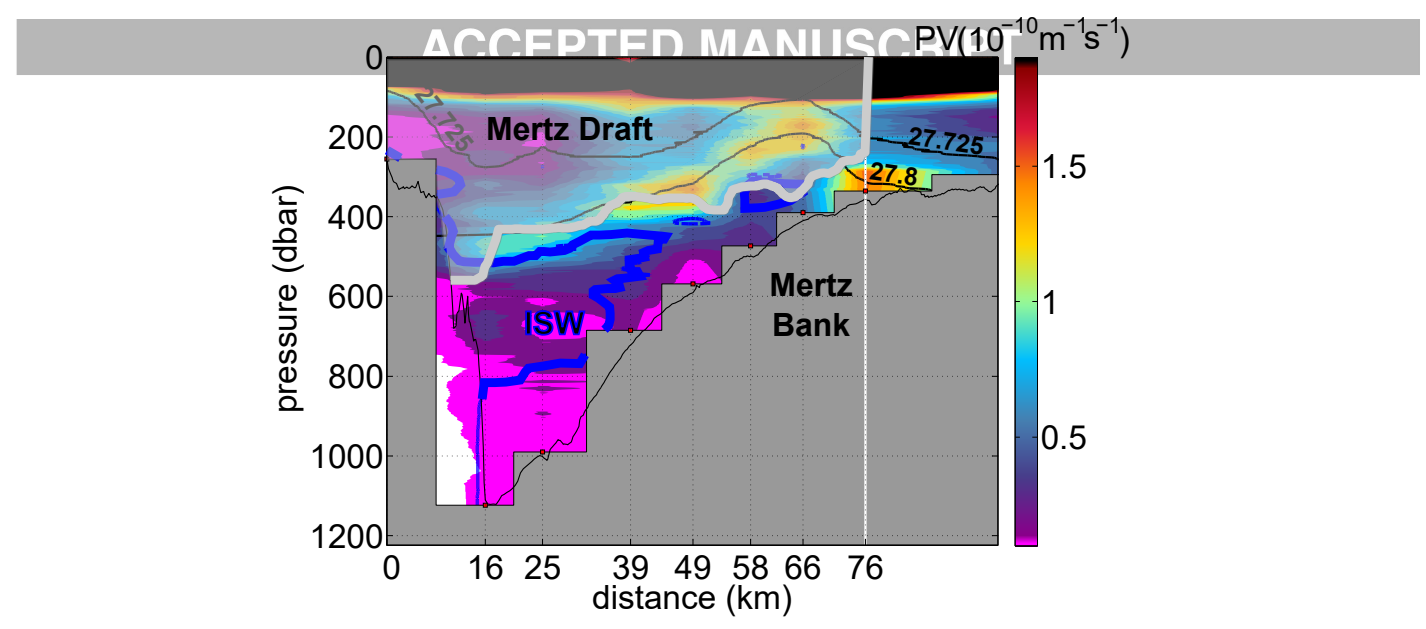

Figure 11: Stretching component of the Ertel potential vorticity (PV) (in $10^{-10} \mathrm{~m}^{-1} \mathrm{~s}^{-1}$ ) along the Mertz section. The PV has been smoothed in the vertical using a 100-m running window. The Mertz draft (transparent area surrounded by a thick grey contour) is from Mayet et al. (2013). Also shown are the 27.725 and the 27.80 isopycnals used as model layer interfaces (black line) and the freezing point, $\theta_{f}$ at 50 dbar isopleth (blue line) defining the ISW.

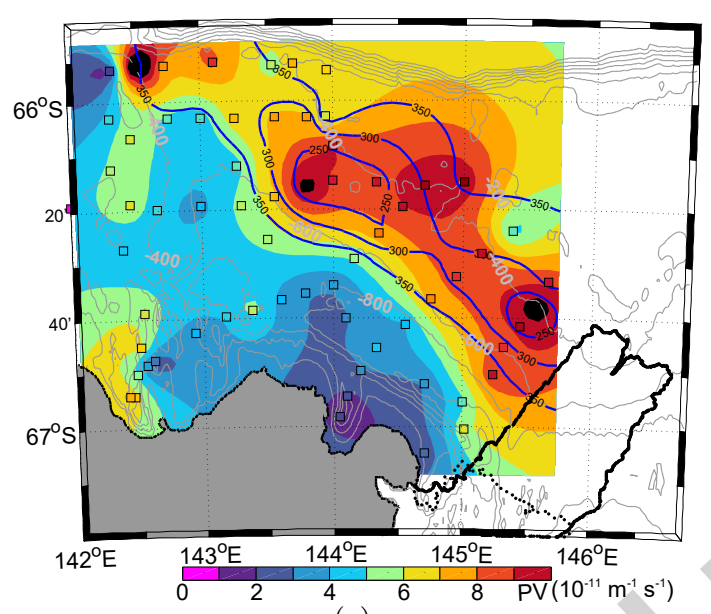

(a)



(b)

Figure 12: Distribution of (a) stretching component of the Ertel potential vorticity (PV) $\left(-f N^{2} g^{-1}\right)$ vertically averaged over the model intermediate layer (in $10^{-11} \mathrm{~m}^{-1} \mathrm{~s}^{-1}$ ) and interpolated on a regular grid using a kriging procedure and (b) the topographic stretching, $f H^{-1}$ (where $\mathrm{H}$ is the thickness of the water column) (in $10^{-7} \mathrm{~m}^{-1} \mathrm{~s}^{-1}$ ). Also shown in (a) are the depth of the $\sigma_{0}=27.8$ isopycnal (blue contour), the location of the CTD stations (open black squares) and the bathymetry (evry $200 \mathrm{~m}$ as grey contours with white labels). The MGT is indicated as a black contour in its pre- (solid line) and post- (dotted line) geometry.

(especially one occurring near $66^{\circ} 20^{\prime} \mathrm{S}$ ), which could be inferred from flow continuity requirements between our CTD sections, corresponded to concordant faults in the DSW dome, driving the flow back into the depression and to the sill (Figure 12 a). In front of the MGT, the same continuity considerations suggested an important lateral inflow to the Adélie Depression interior, following the northwestern side of the MGT from the tip of the glacier across the slope of the Mertz Bank. This flow likely merged with the branch which was flowing over the upper slope of the bank and was forced to recirculate southwestward by the presence of the MGT. The MGT draft, estimated to about $300 \mathrm{~m}$ at the MGT tip, was large enough, especially on the shallow Mertz Bank, to induce substantial shrinking of the water column and barotropic potential vorticity changes (Figure 12 p). Similar arguments have been proposed by Darelius et al. (2014) concerning the Filchner-Ronne Ice Shelf. From the MGT, the recirculation of the mCDW toward the sill was also constrained by the deep density distribution. Additionally, it was likely forced to remain confined over the lower northeastern slope of the Adélie Depression by enhanced horizontal potential vorticity gradients resulting from subsurface lifting of the isopycnals (see $\sigma_{0}=27.725$ at the southern 
end of the section in Figure 11) and stretching of the upper water column near the coast which prevented ${ }_{635}$ the flow from extending too far into this region (note however that the circulation in the southwestern and western Adélie Depression was not properly resolved by our CTD array).

As mentioned above, the dome structure of the dense water, particularly its asymmetry relative to the depression center is a recurrent feature in the summer observations on the AGVL shelf. Kusahara et al. 2011) concluded that the summer circulation simulated in their numerical model could be a relaxation of the winter buoyancy-driven circulation. If this scenario were to be valid, the summer dense water dome could be the result of a collapse of the homogeneous dense water patch formed in winter. In absence of additional forcing, the shape of the patch after cessation of the polynya activity would be expected to reflect the geometry of the region of enhanced sea ice production. Remnants of winter mixing could explain the potential vorticity minimum near the Antarctic coast. Similar deep winter mixed layers were mentioned in summer 2000-2001 in this region by Sambrotto et al. (2003) which were associated with more saline surface waters compared to the depression interior, following a pattern similar to what was observed in summer 2008 (Lacarra et al. 2011$)$. Deep winter mixed layers were also found in summer in Commonwealth Bay (see location in Figure 1), one of the most active part of the MGP (Lacarra et al. 2011: Vaillancourt et al. 2003).

${ }_{650}$ Although very little direct information exists on the ice production in the MGP (Lytle et al. 2001$)$, previous estimates from satellite microwave observations suggested maximum production near the coast, in the vicinity of Buchanan Bay, rather than on the upper slope of the Mertz Bank (Tamura et al. 2012 ). On the other hand, Williams and Bindoff (2003) in winter 1999 observed a dense water chimney centered over the deepest part of the Adélie Depression. Given these results, it is likely that other mechanisms than a pure relaxation of the winter mixed patch contributed to creating or maintaining (from winter though spring) the asymmetric doming structure of the dense water layer observed in summer.

One possibility would be that the wind stress curl contributed to sustained suction in the water column in the region coinciding with the dense water dome. Although the curl deduced from the ERA-I reanalysis might not capture the actual scales of the surface wind, the January climatology does suggest upward velocities associated with surface divergence between $66^{\circ} \mathrm{S}$ and $66^{\circ} 45^{\prime} \mathrm{S}$ (in 2008 these velocities could have generated a $30 \mathrm{~m}$ lift of the isopycnals over the three months corresponding to the period of restratification preceding the ALBION cruise). Near the Antarctic coast, the wind stress curl from ERA-I is not reliable due to the proximity of land. Yet the dominant westward component of the wind in January near the coast, also found in the 2008 observations at the coastal AWS at Cape Denison, should

665 have generated a large scale downwelling which might have participated to the observed southwestward deepening of the deep $\sigma_{0}=27.80$ isopycnal forming on the southwestern flank of the dome. Collapse of the $\sigma_{0}=27.80$ isopycnal in the central Adélie Depression in response to drainage of the dense reservoir by export at the sill or underneath the MGT might also have participated to shaping the dome in spring.

Coastal downwelling at the coast, although not fully resolved by our CTD array, would be consistent with the existence of a barotropic coastal current flowing westward from the MGT, as was simulated by Mayet et al. (2013) with a barotropic tidal model and Kusahara et al. (2011), or suggested by Snow et al. (2016) for the years prior to the Mertz calving. Rising of subsurface isopycnals, as we observed at the coast near Buchanan Bay and Watt Bay, would however suggest that this westward component of the current had a baroclinic structure and was bottom intensified. Although we lack direct evidence 675 of such a structure, it would be capable of transporting some dense water (including the ISW) from the MGT westward. The numerical simulation of Kusahara et al. (2011) indicated that such a deep flow would turn north upon encountering the Adélie Bank and contribute to DSW export at the sill. That the three-dimensional density distribution exerts a baroclinic control on the gyre circulation over the AGVL shelf, altogether limiting near the coast the extent of the northwestward branch of the gyre across 680 the depression and controlling the position of the gyre while responding to the wind stress curl farther off-shore on the shelf, had not been stressed in earlier studies. Snow et al. (2016) argued that the outflow branch of the gyre was the signature of a shelf wide wind-driven coastal downwelling but they did not investigate in detail the baroclinic structure of the current, nor its detailed relationship to the wind stress distribution.

Although the reconstructed DSW circulation in the inverse model is subject to large uncertainties, our conclusion that no dense water in the range $\sigma_{0}>27.88$ was being exported at the Adélie Sill in January 2008 is likely to be robust. Similarly, Williams et al. (2008) analyzing data from a mooring located upstream of the sill in 1999-2000 found no evidence of this dense mode after January 8, 2000. 
Our inverse model also suggests insignificant net outflow associated with the less dense varieties of DSW

which were observed in relatively small volume in the western part of the sill. In the same time, a significant transport of DSW was found to flow from underneath the MGT. Gradual weakening of this vein of DSW as it travelled across the Adélie Depression toward the sill was not counterbalanced by equal amounts of recirculated water which would indicate that it was diluted through mixing with ambient water masses. Note that, according to our mooring observations, this outflow of DSW from underneath the MGT, which was mostly distributed within the 400-700 m layer (Figure 6 and 9e) would be a seasonal feature and would give way to a reversed deep circulation in winter with DSW flowing into the MGT, as already suggested by, e.g., Cougnon et al. (2013).

Our summer 2008 results differ from earlier numerical model estimates of the mean seasonal outflow at the Adélie Sill which suggested export of order 0.1-0.2 Sv in the $\sigma_{0}>27.80$ density range in January Kusahara et al. 2011, further corrected to account for their numerical model bias). A possible explanation would be that, in 2008, the DSW outflow had ceased earlier than average in the season. Rough estimates of the time evolution of the isopycnal depths prior to the ALBION cruise suggest that, contrary to the relative steadiness observed during this cruise, substantial vertical velocities were still present in the interior water column in the preceding month. The latter were estimated using the stratification evolution observed between December 2007 (the time of the CEAMARC cruise) and early January (the time of the ALBION 2008 cruise). A linear regression (in which the spatial variability was taken into account as a random noise) of the depths of selected isopycnals over time was performed in the common domain covered by the CEAMARC and ALBION cruise and revealed downward displacements of the 27.80 isopycnal surface on the order of $5.3 \pm 1.1 m d a y^{-1}\left(R^{2}=0.4\right.$, p-value $\left.<0.001\right)$. For the 27.725 isopycnal, the downward displacements were half this value. Part of the collapse of the dense water bulge in the depression (for an equivalent diapycnal mass transport of $0.51 \mathrm{~Sv}$ ) prior to the ALBION cruise might have reflected ongoing export of dense water at the sill. This scenario would be consistent with observed decrease of the intermediate layer Ertel potential vorticity in the western Adélie Depression and at the sill between the two cruises (not shown) which would trace decreasing volume of the dense water layer in the export region during that period. It should be noted that, in view of the seasonal evolution of the isopycnal geometry (as evidenced here in the CEAMARC period), one should be cautious when using steady state assumption in the context of inverse modelling.

\subsection{Modification of the $m C D W$ on the AGVL shelf and interaction with the Mertz Glacier}

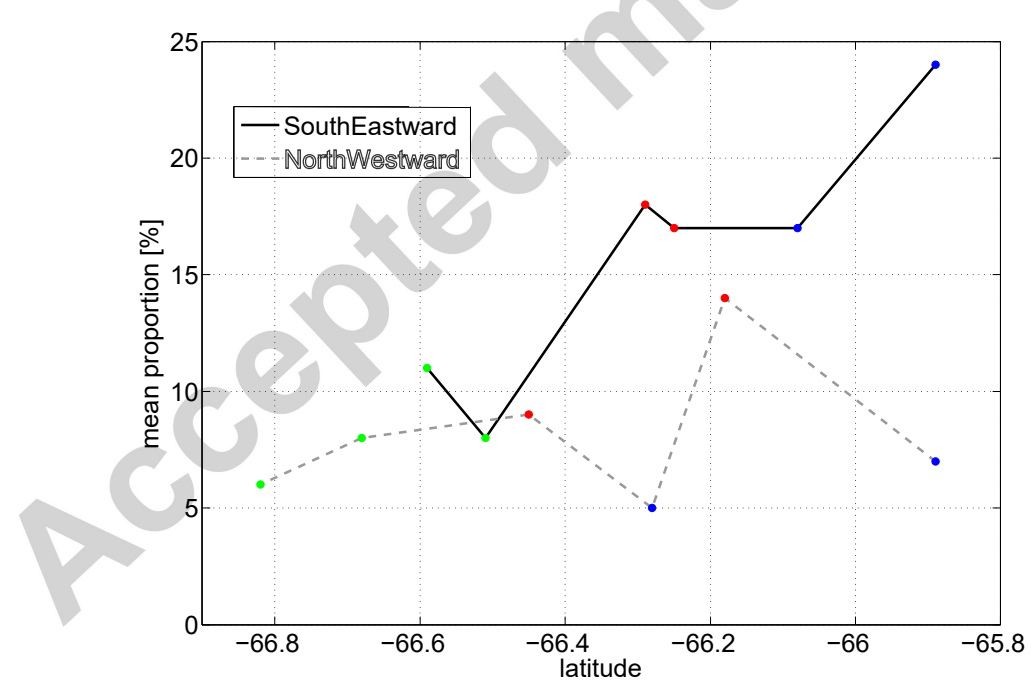

Figure 13: Meridional evolution of the mean percentage of mCDW end-member along the inflow (solid black line) and outflow (dashed grey line) branches of the gyre circulation.

The contrast between Figure $10 \mathrm{c}$ and $\mathrm{d}$, in particular absence of the less diluted mode of mCDW in the southern part of the Adélie Depression, suggests progressive dilution of the mCDW on its way from the Adélie Sill to the MGT. Figure 13 shows that the mean concentration of mCDW end-member in the inflow branch decreased from roughly $25 \%$ at the sill to about $10 \%$ near the MGT. Consistently the averaged concentration in the outflow branch was half that in the inflow branch. Dilution may be 
partly the result of exchanges with more-diluted modes of mCDW present on the Mertz Bank. While 725 a strong dilution along the inflow branch occured within the Sill box, probably as a result of eastward recirculation of some water from the more diluted return branch, another one was identified between the Depression box and the Mertz box, which could be the result of an inflow of more diluted mCDW from the Mertz Bank. Similarly, a large decrease in concentration between the inflow and outflow branch was observed along the Mertz section which we could relate to additional supply of a diluted mCDW mode to the gyre circulation from the Mertz Bank. This supply would be consistent with the net volume, heat and fresh water transports through the Mertz section as discussed in section 4.2.3.

While interaction of the mCDW with the Antarctic glaciers or ice shelves has been shown to occur at several locations on the West Antarctic shelf, including the Amundsen shelf (e.g. Ha et al., 2014), these were much less documented on the East Antarctic shelf $($ Herraiz-Borreguero et al. $\mid$ 2015). Still large glacier retreats were diagnosed in some regions like the Totten Glacier (Liu et al.| 2015). For the MGT, indirect observations of glacial melt in winter were first provided by Bindoff et al. (2001) based on an observed transport of $0.5 \mathrm{~Sv}$ of ISW outflowing from underneath the MGT. This scenario was confirmed by the simulations of Cougnon et al. $(2013)$, but a warm bias in the simulated DSW properties may have affected the results. Very recently, Kusahara et al. (2017), performing simulations with an ocean-ice shelf model, showed that the time-space distribution of the MGT melt rate at its annual peak in summer coincided with that of the warm mCDW intrusions, and they suggested that melting was achieved by mCDW interacting with the glacier tongue. We consider hereafter two possible sources of glacial melt, one involving the mCDW which mainly contribute to lateral melt along the side walls of the glacier tongue (see Figure 11 for the position of the mCDW core relative to the immerged part of the MGT) and the other implying the DSW which is transformed into ISW through basal melt. According to our transport estimates through the Mertz section (calculated relative to the mean temperature, $\theta_{r e f}=-1.393^{\circ} \mathrm{C}$, and salinity, $S_{\text {ref }}=34.499$, of the mCDW layer on this section), a net import of $94 \pm 14$ GW to the MGT area was achieved by the $\mathrm{mCDW}$ (end-member concentration $>10 \%$ ). In the same time a net fresh water export of $0.073 \pm 0.011 \mathrm{mSv}$ exited this area with the outflowing branch of $\mathrm{mCDW}$. A question therefore arises as to the origin of the heat sink and fresh water source which could balance these exchanges and maintain stationary conditions near the MGT, and to which extent glacial melt could be involved in this balance. Two possible scenarios have been considered, one involving exclusively the lateral inflow of $0.19 \pm 11 \mathrm{~Sv}$ from the Mertz Bank, and the other one allowing for a contribution from glacial melt through interaction of the mCDW with the sides of the MGT. In the first scenario no such melting being allowed, the lateral inflow must have supplied a relatively cold, fresh (or diluted) mode of mCDW with characteristics $\theta_{\text {in }}<\theta_{\text {ref }} ; S_{\text {in }}<S_{\text {ref }}$ ) to the Adélie Depression (assuming that the region located between the MGT and the Mertz section had the same mean temperature and salinity as on the Mertz section). In the second scenario, given that the net heat available through the Mertz section was more than four times as large as the heat necessary to produce a melt water amount equivalent to the net fresh water returned through the section, different melt rates could be obtained depending on the assumption made on the proportion of heat actually used as latent heat of melting. A lower limit of $0.073 \pm 0.011 \mathrm{mSv}$ (or $0.66 \pm 0.10 \mathrm{~m} \mathrm{an}^{-1}$ for a $35 \mathrm{~km} \times 100 \mathrm{~km}$ floating ice tongue, Lescarmontier, 2012) for the glacier melt rate was obtained by postulating that this rate was just equal to the fresh water export through the Mertz section, a cold $\left(\theta_{i n}<\theta_{\text {ref }}, S=S_{\text {ref }}\right)$ lateral inflow being able to compensate for the extra 765 heat import through the section. Alternatively, an upper limit of $0.306 \pm 0.046 \mathrm{mSv}$ (or $2.76 \pm 0.41 \mathrm{~m}$ $\mathrm{an}^{-1}$ ) was obtained for the glacier melt rate by assuming that all the heat imported through the Mertz section was available for glacier melting while a saline $\left(S_{i n}>S_{r e f}, \theta=\theta_{r e f}\right)$ lateral inflow provided the necessary salt to the region near the MGT to compensate for the excess of glacial meltwater. Note that our equivalent annual melt rates should be considered upper limit estimates as glacial melt is likely to be

770 a seasonal process with decreasing amplitude in winter when the mCDW does not penetrate far enough on the shelf to reach the glacier.

A similar heat and freshwater budget performed on the DSW, considered as the precursor of the ISW, was also used to estimate basal glacier melting. The $0.05 \mathrm{~Sv}$ of ISW transported through the Mertz section were assumed to be produced by a similar volume of DSW which would have incorporated meltwater through interaction with the underneath of the MGT. The DSW precursor was assumed to be at the freezing point (relative to $50 \mathrm{dbar}$ ) and to have such salinity that, in the $\theta$-S space, it would fall on the Gade line passing through the mean temperature and salinity of the ISW. A glacial melt rate of $0.03 \pm 0.03 \mathrm{mSv}$ (or $0.27 \pm 0.27 \mathrm{~m} \mathrm{an}^{-1}$ ) and $0.05 \pm 0.02 \mathrm{mSv}$ (or $0.44 \pm 0.18 \mathrm{~m} \mathrm{an}^{-1}$ ) was calculated depending on whether it was deduced from the amount of heat that the DSW must have released to the 

ISW temperature and salinity, respectively. These melt rates are in both cases smaller than the lower bound of those inferred from mCDW-glacier interactions.

Despite the above calculations suggest that significant glacier melt could possibly occur through interaction of the warm mCDW with the sides of the glacier, the lateral area of the MGT is likely to be too small (200 times smaller than its underside area) to support this hypothesis. Lateral advection of a fresher and colder water mass to explain cooling and freshening of the mCDW near the MGT is appears more plausible. Alternatively, our range of non-zero melt rates falls in the range of annual glacial melt rates of $1.2 \pm 0.4 \mathrm{~m} \mathrm{yr}^{-1} 3.8 \pm 1.5 \mathrm{~m} \mathrm{yr}^{-1}$ reported by Cougnon et al. (2013) in a numerical simulation of the area, but is below the range of the January melt rate $\left(8 \pm 0.9 \mathrm{~m} \mathrm{yr}^{-1}\right.$ in equivalent annual melt rate) calculated by Kusahara et al. (2017) for the condition before the MGT calving, part of the discrepancy with the latter study being possibly due to too a shallow mCDW core in the model, enhancing the interaction with the glacier. Cougnon et al. (2013) suggest that the melt rate depends on the activity of the polynya, which would qualify winter 2007-2008 as a winter of medium activity, as actually suggested by the atmospheric heat flux time-series (their figure $2 \mathrm{~b}$ ). In their simulation, glacier melting did occur in summer during years of weak polynya activity and was achieved primarily by enhanced presence of relatively warmer water interacting with the base of the ice shelf. In summer 2008, our calculations give smaller basal melt rates values than those reported by Liu et al. (2015) $\left(0.6-2 \mathrm{~m} \mathrm{yr}^{-1}\right)$ for the Mertz Glacier in a large scale study of the Antarctic glaciers, most probably because only small amounts of ISW were found to be exported to the Adélie Depression from underneath the Mertz. Our ISW transport of $0.05 \mathrm{~Sv}$ was ten times smaller than the transport found in winter 1999 by Williams and Bindoff (2003). One likely reason is that our Mertz section was missing an important part of the ISW outflow which would take place closest to the Antarctic coast. Nevertheless, our study suggests that both lateral melt and basal melt were plausibly impacting the Mertz Glacier mass balance in summer 2008, in proportions which have still to be determined.

\section{Summary and concluding remarks}

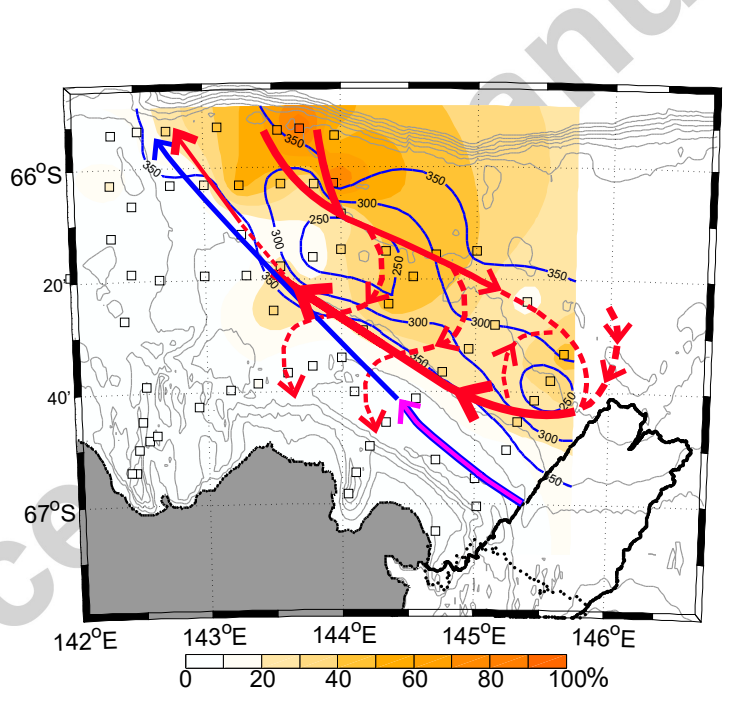

Figure 14: Sketch of the circulation of the mCDW (red arrows), the ISW (magenta arrow) and the water masses with high (>50\%) concentration of DSW (blue arrow), superimposed on the concentration of mCDW end-member in the mCDW maximum concentration in the water column (filled orange contours). Also shown is the depth of the $\sigma_{0}=27.8$ isopycnal (blue contour).

A circulation scheme for the mCDW on the East Antarctic shelf off the AGVL Land (Figure 14) was proposed based on simple geostrophic dynamics. While this simplified framework was found very useful to study the first order budgets of the shelf and their consequences on the ocean-glacier interaction, the retrieved circulation should be taken with caution in view of the neglected dynamics. Eddies, which were definitely not resolved by our observational array, are known to play a significant role in the exchanges of $\mathrm{mCDW}$ at the shelf break as well as in its interaction with the glacial features Herraiz-Borreguero 
et al., 2015). In particular, potentialvorticity budgets (Thompson et al., 2014) and idealized numerical simulations (Stewart and Thompson, 2015) indicate substantial eddy contribution to these exchanges.

Our results suggest a strong impact of the annual cycle of DSW formation on the circulation and As the latter implies an important role of the density distribution in constraining the circulation, effort should be put on improving the representation of the full seasonal cycle of the water mass properties and formation process in models. So far this representation remains approximate.

Our analysis was dedicated to the pre-calving situation when the Mertz Glacier was still acting as an efficient physical barrier to ocean currents and sea ice drift. In particular, it was argued that the mCDW was recirculating along the MGT, a process which should increase the residence time of this water mass and its capacity to provide heat to the ambient waters in the Adélie Depression. Calving of part of the glacier in February 2010 may have induced severe reorganization of the circulation impacting in particular the ice-ocean interactions. Following the MGT calving, the inflow of mCDW might have the heat storage in the Adélie Depression while, on the other hand, reduced DSW production might have favored farther penetration of the $\mathrm{mCDW}$ in the Adélie Depression. To evaluate and understand the net effect of these multiple changes on the shelf dynamics and, more generally, on the environmental conditions of the region, it is highly desirable that adequate observational programs be pursued. IPEV. The lead author is supported by a doctoral fellowship from the French Minister of Education and Research (gs3) (MESR).

\section{Appendix A. Determination of mooring orientation}

We want to estimate the constant orientation angle of the ADCP mooring in the horizontal plane. The estimate is performed by searching for the orientation which provides the best (in a least square sense) fit between the principal axis of the tidal constituent ellipse extracted from the ADCP measurements and those simulated by a barotropic tidal model (T-UGOM, see Mayet et al. 2013 ). The different constituents of the barotropic tide were extracted from the vertically averaged ADCP velocities using the t_tide software (Pawlowicz et al., 2002). Vertical averaging was performed over the depth range warranting the retrieval of $50 \%$ of good data at any considered level and excluded the frictional bottom layer. Only those constituents which were significant with respect to the t_tide SNR (squared ratio of amplitude to error) criterion $(S N R>1)$ were selected. Estimates of the mooring orientation angle were obtained by searching, separately for each of the selected tidal constituents, the best fit between the tidal ellipse orientations derived from the model and from the observations. The best estimate of the mooring orientation was finally obtained by averaging the orientations angles deduced for each constituent after weighing each constituent angle by a factor proportional to the angle significance as retrieved from $\mathrm{t} \_t$ tide. 


\section{Appendix B. Optimal multi-parameter analysisANUSCRIPT}

Water masses encountered on the AGVL shelf were assumed to derive from four source water masses or end-members: the AASW, the WW, the mCDW and the DSW, the latter encompassing both the DSW and the ISW in order to limit the number of degrees of freedom and to avoid the difficulty in discriminating the two water masses from each other. Instead, the proportion of ISW contained in the DSW volume identified from the OMP analysis was extracted based on an arbitrary upper temperature limit (freezing point at $50 \mathrm{dbar}$ ). The properties of the four end-members are listed in Table B.4 and reported in the $\theta$-S space in Figure B.15. For the AASW, the properties of the top (0-10 m) layer averaged over the box model domain (i.e. the three model boxes, see section 3.2.2) were used. For the mCDW (DSW), we chose the properties of the least oxygenated (most saline) water amongst all the CTD casts used in the inverse model analysis. As WW end-member, we selected water which could be considered a common precursor of the shelf mode and the off-shore mode 1 . The OMP allowed us to define water parcels as mixtures of the four end-members in various proportions. This approach was found useful on the AGVL shelf where high levels of mixing are anticipated. Four conservation equations for mass, heat, salt and dissolved oxygen were formulated for each set of observed values of these four parameters, and were solved for the relative concentrations in the different end members. These conservations were only applied to water parcels which did not reach to the surface (deeper than $50 \mathrm{~m}$ depth) to exclude possible influence of air-sea exchanges.

\begin{tabular}{ccccc}
\hline Water mass & Acronym & $\begin{array}{c}\text { Potential temperature } \\
\theta\left({ }^{\circ} \mathrm{C}\right)\end{array}$ & $\begin{array}{c}\text { Salinity } \\
\mathrm{S}(\mathrm{psu})\end{array}$ & $\begin{array}{c}\text { Dissolved Oxygen } \\
\mathrm{O}_{2}\left(\mu \mathrm{mol} \mathrm{l} l^{-1}\right)\end{array}$ \\
\hline Antarctic Surface Water & & -0.089 & 34.19 & 367 \\
Winter Water & AASW & -1.886 & 34.36 & 312 \\
Modified Circumpolar Deep water & mCDW & 0.03 & 34.595 & 244 \\
Dense Shelf Water & DSW & -1.917 & 34.711 & 323 \\
Ice Shelf water & ISW & Variety of DSW with $\theta<\theta_{f}$ (50dbar $)$ \\
\hline
\end{tabular}

Table B.4: Properties of each water mass end-member used in the OMP analysis

\section{Appendix C. Box inverse model}

\section{Appendix C.1. Model equations}

For the $k^{t h}$ layer bounded by a closed hydrographic section with area $A_{k}^{v}$, the conservation of a given tracer, $C$, can be written as :

$$
\iint_{A_{k}^{v}} \rho C V_{n} d x d z+\left[A^{h}\left(w^{*} \overline{\rho C}+D^{c}\right)\right]_{k+1}^{k}=S_{k}^{c}
$$

In (C.1), the left hand side of the equation represents the horizontal divergence of the tracer fluxes associated with the geostrophic flow (first term) and diapycnal exchanges through the upper and lower isopycnal boundaries (sum of the second and third terms) as defined in equation (C.2 below, and the right hand side, $S_{k}^{c}$, gathers external tracer sources and sinks (e.g. air-sea exchanges if the control volume extends to the surface) and neglected ageostrophic and time dependent contributions. $V_{n}$ is the horizontal velocity component normal to the lateral boundary of the box. Index $k$ refers to the lower boundary of the $k^{t h}$ layer and $k-1$ to the upper boundary. $A_{k}^{h}$ is the area of the isopycnal surface defining the upper boundary of the $k^{t h}$ layer while $\rho_{k} C_{k}$ is the averaged tracer concentration on this surface (the overbar denotes area averaging), $w_{k}^{*}$ is the diapycnal advective velocity through the surface and $D_{k}^{c}$ is the effective diffusive flux defined as (McIntosh and Rintoul, 1997; Sloyan and Rintoul, 2000, Naveira Garabato et al. 2003):

$$
D_{k}^{c}=\overline{\rho_{k} C_{k}} w_{k}^{* c}-\overline{\rho_{k} C_{k}} w_{k}^{*}=-\kappa^{*}\left(\overline{\frac{\partial \rho C}{\partial_{z}}}\right)_{k}
$$

\footnotetext{
${ }^{1}$ The WW end-member temperature was chosen to be at the 50 dbar freezing point with salinity lying on the mixing line obtained by regression between the $\mathrm{mCDW}$ end-member and the warmer shelf break mode of WW, which gives $\theta=$ $-1.886^{\circ} \mathrm{C}$ and $\mathrm{S}=34.360$. The dissolved oxygen content of the $\mathrm{WW}$ was selected based on similar regression in the $\mathrm{O}_{2}-\mathrm{S}$ space and picking up the $\mathrm{O}_{2}$ value corresponding to the selected salinity.
} 




Figure B.15: $\theta$-S diagram of the CTD casts collected on the Sill section (see Figure 1 for the location of the section). End-member water masses include: Antarctic Surface Water (AASW), modified Circumpolar Deep Water (mCDW), Dense Shelf Water (DSW) and Winter Water (WW). The dashed black line represents the freezing point of seawater at 50 dbar (see explanation in text). Dots are colored according to the associated transport across the section (northward and southward transports are shown in red and blue colors, respectively). All of the CTD-profiles (small grey dots).

In $(\mathrm{C} .2), \overline{\rho_{k} C_{k}} w_{k}^{* c}$ is the net diapycnal flux of tracer $C$ through the $k^{\text {th }}$ isopycnal surface and the right hand side term parameterizes diapycnal diffusion with $\kappa^{*}$ being the effective diffusivity coefficient (Sloyan and Rintoul, 2000, Ganachaud, 2003). This effective diffusivity is specific to each tracer (excluding mass) and parameterizes all diapycnal processes which cannot be represented by a mean diapycnal advective velocity $w^{*}\left(\right.$ Sloyan and Rintoul, 2000). In practice, the inverse model is solved for $w^{*}$ and for effective diffusive fluxes $D_{k}^{c}$ of all tracers. Mass conservation is derived by setting $C=1$ and $D_{k}^{\text {mass }} \simeq 0$ for all $k$. In all layers but the surface layer we assume $S_{k}^{c}=0$ as a first guess. In practice, the salt and heat conservations are formulated relative to a reference tracer value (taken here as the estimated average of the tracer over the considered layer volume, see Table C.5). As explained by (Wunsch, 2006), this formulation reduces the impact of possible mass imbalance on the tracer imbalance.

\begin{tabular}{ccccccc}
\hline & \multicolumn{2}{c}{ Layer 1 } & \multicolumn{2}{c}{ Layer 2 } & \multicolumn{2}{c}{ Layer 3 } \\
& $\theta\left({ }^{\circ} \mathrm{C}\right)$ & $\mathrm{S}$ & $\theta\left({ }^{\circ} \mathrm{C}\right)$ & $\mathrm{S}$ & $\theta\left({ }^{\circ} \mathrm{C}\right)$ & $\mathrm{S}$ \\
\hline Sill box & $-1.11 \pm 0.56$ & $34.35 \pm 0.10$ & $-1.36 \pm 0.45$ & $34.50 \pm 0.03$ & $-1.85 \pm 0.16$ & $34.60 \pm 0.04$ \\
Depression box & $-0.98 \pm 0.65$ & $34.35 \pm 0.10$ & $-1.57 \pm 0.30$ & $34.49 \pm 0.02$ & $-1.85 \pm 0.16$ & $34.60 \pm 0.04$ \\
Mertz box & $-1.35 \pm 0.53$ & $34.35 \pm 0.10$ & $-1.36 \pm 0.45$ & $34.50 \pm 0.03$ & $-1.85 \pm 0.16$ & $34.60 \pm 0.04$ \\
\hline
\end{tabular}

Table C.5: Mean hydrographic properties of the inverse model boxes

900

In C.1 the tracer divergence in the bottom friction layer is ignored. In the surface layer, $S_{1}^{c}$ includes the tracer convergence associated with the Ekman transport through the lateral boundaries :

$$
S_{1}^{c}=-\oint \frac{\vec{\tau}}{f}\left(\frac{1}{h_{E}} \int_{-h_{E}}^{0} C d z\right) \cdot \overrightarrow{d l}
$$

where $h_{E}$ is the Ekman layer thickness, $\tau$ is the surface wind stress and $\overrightarrow{d l}$ is the unit vector aligned with the lateral boundary of the control volume.

The conservation constraint (C.1) can be applied simultaneously to several layers and/or tracers. Upon discretizing the horizontal integral into a sum of tracer fluxes estimated at $N_{b}$ station pairs, C.1. translates into a system of equations which can be written as:

$$
A x+n=-\Gamma
$$

where $x=\left[\left\{b_{i}\right\} ;\left\{w_{k}^{*}\right\} ;\left\{D_{k}^{c}\right\}\right], k=1, N_{w}, i=1, N_{b}$, is the column vector of the unknowns with $N_{w}$ the number of layers, $N_{b}$ the number of reference velocities to be estimated at each station pair, and 
$N=N_{b}+2 N_{w}$ the number of unknowns. $A$ is the $M \times N$ observation matrix, with the $N$ columns corresponding to the $N$ unknowns (the reference level velocities, the diapycnal velocities and the diffusive fluxes between layers) and the $M$ rows corresponding to the $M$ constraints. In agreement with (Wunsch, 1978), the column of matrix $A$ corresponding to the bottom velocity are weighed according to the vertical area associated with the station pair. We call $\Gamma$ the column vector of the observations which contains the initial imbalance in the tracer constraint estimate. Since the number of constraints $M$ is usually smaller than the number of unknowns $N$, the system (C.4) is underdetermined. The solution of (C.4) can be estimated using the Gauss-Markov approach (see Wunsch, 2006, for a presentation of this approach).

\section{Appendix C.2. First guess on diapycnal velocities : means and uncertainties}

A rough estimate of a first guess on the diapycnal velocities could be obtained from examination of the time evolution of the density distribution based on temperature, salinity and pressure recorded by the microcats at the MG mooring and linearly interpolated between the measurement levels. Linear regression of the depth of the $\sigma_{0}=27.725$ and $\sigma_{0}=27.80$ isopycnals on time could thus be performed over the period of minimum kinetic energy identified in section 4.1 and suggested that, over that period, small subsidence occurred in the water column which was associated with diapycnal velocities $w^{*}$ of order $0.1 \pm 0.510^{-6} \mathrm{~m} \mathrm{~s}^{-1}$ and $4.3 \pm 0.510^{-6} \mathrm{~m} \mathrm{~s}^{-1}$ for the $\sigma_{0}=27.725$ and $\sigma_{0}=27.80$ isopycnal, respectively. In view of these small velocities, we assumed as first guess that diapycnal exchanges of mass and tracers were equal to zero $\left(w^{*}=0, D^{c}=0\right)$.

As for the reference velocity, the Gauss-Markov approach requires estimating an a-priori uncertainty on the diapycnal velocities. An uncertainty of $1.5 \pm 1.710^{-5} \mathrm{~m} \mathrm{~s}^{-1}$ was assumed in order for the resulting uncertainty on the diapycnal volume flux (estimated to $0.15 \mathrm{~Sv}$ when integrated over the whole Adélie Depression area of about $10^{4} \mathrm{~km}^{2}$ ) to be one order of magnitude less than the uncertainty on the advective transport associated with the reference velocity (estimated to $3 \mathrm{~Sv}$ when integrated over a lateral boundary of about $210^{2} \mathrm{~km}^{2}$ ). This scaling is equivalent to allowing the imbalance in the tracer conservation constraints to be mainly accommodated by adjustment of the reference velocity with diapycnal exchanges playing a minor role (see Wunsch, 2006, for a discussion on this subject). Uncertainty on the diapycnal tracer fluxes $D_{k}^{c}$ across a given isopycnal surface level $k$ was estimated from the product of the diapycnal velocity uncertainty with the isopycnal area-average of the tracer anomaly relative to the reference value. Depending on the level, uncertainty estimates were found to vary in the range 0.6-1.6 $\mathrm{kg} \mathrm{m}^{-2} \mathrm{~s}^{-1}$ and 5-20 W $\mathrm{m}^{-2}$ for salt and heat, respectively. According to equation (C.2), this would be equivalent to selecting an effective diffusivity of $10^{-3} \mathrm{~m}^{2} \mathrm{~s}^{-1}$.

\section{Appendix D. Estimation of the different sources of observation noise}

We detail in this section the various sources of random error taken into account in our observations. Their actual impact on the a-priori estimation of the conservation constraints was evaluated by estimating the amplitude of the associated anomalies on the density field (the observation vector). These anomalies are then introduced in the constraints, either as random noise perturbations (and their effect estimated taking the variance of the outputs of Monte-Carlo experiments) or deterministic perturbations (and their effect estimated by the rms difference from a control case).

The error due to the instrumental noise (see Lacarra et al. 2011 ) was tested with a random noise added to the density field with magnitude corresponding to $0.01^{\circ} \mathrm{C}$ in temperature and 0.01 in salinity, and was found to be negligible compared with other sources of error. The error due to inadequate mapping of the bottom flow over uneven topography (Ganachaud, 2003) (the Jacobsen and Jensen method being based on strong simplification of the density distribution below the DCL) was tested using two additional estimates of the bottom flow between stations pairs based on: (i) a reference level at the DCL and a no motion layer below and (ii) a reference level at the bottom depth at the deeper station. The related error on the total volume convergence for each box is in the range 0.03-0.14 Sv.

Another expected source of error was under-sampling of the relevant spatial flow scales, the mean station spacing of $14 \mathrm{~km}$ (with extrema of 7 and $40 \mathrm{~km}$ ) being about twice the mean internal Rossby radius $(9 \pm 4 \mathrm{~km})$. The temperature and salinity field suggest that the geometry of the dense water dome on the northeastern Adélie Depression slope or some of the mCDW features were poorly resolved by the 
tested the sensitivity of the mass conservation constraint to the random removal of one CTD station. The error estimate may however be questionable as it implicitly assumes that the impact of under-sampling would be the same in all range of spatial flow scales, which is obviously not the case. The related error on the total volume convergence was in the range $0.03-0.07 \mathrm{~Sv}$ which is on same order as the error associated with the bottom flow estimate

Tidal motions are important on the Antarctic shelf, with amplitude of surface waves reaching up to $30 \mathrm{~cm}$ (Mayet et al. 2013) and impacting the pressure field. This impact was estimated by randomly adding vertically uniform pressure anomalies to the pressure measured at the CTD stations. The anomaly magnitude was estimated from the standard deviation of 200 pressure sequences randomly extracted in time from the MG mooring bottom pressure record. The net transport error due to this tidal noise on the pressure sensor was negligible compared with the other sources of error.

A major source of error was likely to be due to high frequency processes (such as Internal Gravity Waves, IGW) which could not be sampled with the CTD array. An estimate of their overall impact on the density field was obtained an estimate of the variance of the isopycnal vertical displacements deduced from the IGW strain variance in a selected range of vertical wavelengths (10-150 m, see Kunze et al. 2006). This error was found to be dominant, ranging between 0.1 and $0.22 \mathrm{~Sv}$ depending on the model box, and most notably for the Mertz box. 
Aoki, S., S. R. Rintoul, S. Ushio, S. Watanabe, and N. L. Bindoff (2005), Freshening of the Adélie Land

Aoki, S., Y. Sasai, H. Sasaki, H. Mitsudera, and G. D. Williams (2010), The cyclonic circulation in the Australian-Antarctic Basin simulated by an eddy-resolving general circulation model, Ocean Dynamics, $60(3), 743-757$. doi:10.1007/s10236-009-0261-y.

Aoki, S., Y. Kitade, K. Shimada, K. I. Ohshima, T. Tamura, C. C. Bajish, M. Moteki, and S. R. Rintoul (2013), Widespread freshening in the Seasonal Ice Zone near $140^{\circ} \mathrm{E}$ off the Adélie Land Coast, Antarctica, from 1994 to 2012: Freshening in Antractic Ice Zone, Journal of Geophysical Research: Oceans, 118(11), 6046-6063. doi:10.1002/2013JC009009.

Assmann, K., H. Hellmer, and A. Beckmann (2003), Seasonal variation in circulation and water mass distribution on the Ross Sea continental shelf, Antarctic Science, 15(1), 3-11. doi:10.1017/ S0954102003001007.

Beaman, R. J., P. E. O'Brien, A. L. Post, and L. De Santis (2011), A new high-resolution bathymetry model for the Terre Adélie and George V continental margin, East Antarctica, Antarctic Science, 23(01), 95-103. doi:10.1017/S095410201000074X.

Bindoff, N. L., M. A. Rosenberg, and M. J. Warner (2000), On the circulation and water masses over the Antarctic continental slope and rise between 80 and $150^{\circ} \mathrm{E}$, Deep Sea Research Part II: Topical Studies in Oceanography, 47(12-13), 2299-2326. doi:10.1016/S0967-0645(00)00038-2.

Bindoff, N. L., G. D. Williams, and I. Allison (2001), Sea-ice growth and water-mass modification in the Mertz Glacier polynya, East Antarctica, during winter, Annals of Glaciology, 33(1), 399-406. doi:10.3189/172756401781818185.

Bintanja, R., G. J. van Oldenborgh, S. S. Drijfhout, B. Wouters, and C. A. Katsman (2013), Important role for ocean warming and increased ice-shelf melt in Antarctic sea-ice expansion, Nature Geoscience, 6(5), 376-379. doi:10.1038/ngeo1767.

Budillon, G., M. Pacciaroni, S. Cozzi, P. Rivaro, G. Catalano, C. Ianni, and C. Cantoni (2003), An optimum multiparameter mixing analysis of the shelf waters in the Ross Sea, Antarctic Science, 15(1), 105-118. doi:10.1017/S095410200300110X.

Carmack, E. C., and T. D. Foster (1975), Circulation and distribution of oceanographic properties near the Filchner Ice Shelf, Deep Sea Research, 22(2), 77-90. doi:10.1016/0011-7471(75)90097-2.

Cavalieri, D. J., and S. Martin (1985), A passive microwave study of polynyas along the Antarctic Wilkes Land coast, in Antarctic Research Series, vol. 43, edited by S. Jacobs, pp. 227-252, American Geophysical Union, Washington, D. C.

Cougnon, E. A., B. K. Galton-Fenzi, A. J. S. Meijers, and B. Legrésy (2013), Modeling interannual dense shelf water export in the region of the Mertz Glacier Tongue (1992-2007): Modeling Interannual Dense Shelf Water, Journal of Geophysical Research: Oceans, 118(10), 5858-5872. doi: 10.1002/2013JC008790.

Darelius, E., K. Makinson, K. Daae, I. Fer, P. R. Holland, and K. W. Nicholls (2014), Hydrography and circulation in the Filchner Depression, Weddell Sea, Antarctica, Journal of Geophysical Research: Oceans, 119(9), 5797-5814. doi:10.1002/2014JC010225.

Dee, D. P., et al. (2011), The ERA-Interim reanalysis: configuration and performance of the data assimilation system, Quarterly Journal of the Royal Meteorological Society, 137(656), 553-597. doi: $10.1002 /$ qj. 828

Dinniman, M. S., J. M. Klinck, and W. O. Smith (2011), A model study of Circumpolar Deep Water on the West Antarctic Peninsula and Ross Sea continental shelves, Deep Sea Research Part II: Topical Studies in Oceanography, 58(13-16), 1508-1523. doi:10.1016/j.dsr2.2010.11.013. 
Dragon, A.-C., M.-N. Houssais, C. Herbaut, and J.-B. Charrassin=(2014), A note on the intraseasonal variability in an Antarctic polynia: Prior to and after the Mertz Glacier calving, Journal of Marine Systems, 130, 46-55. doi:10.1016/j.jmarsys.2013.06.006.

Foldvik, A., T. Gammelsrd, E. Nygaard, and S. sterhus (2001), Current measurements near Ronne Ice Shelf: Implications for circulation and melting, Journal of Geophysical Research: Oceans, 106(C3), 4463-4477. doi:10.1029/2000JC000217.

Ganachaud, A. (2003), Error budget of inverse box models: The North Atlantic, Journal of Atmospheric and Oceanic Technology, 20(11), 1641-1655.

Gill, A. E. (1973), Circulation and bottom water production in the Weddell Sea, in Deep Sea Research, vol. 20, pp. 111-140, Elsevier.

Gordon, A. L. (1971), Oceanography of Antarctic waters, in Antarctic Research Series, vol. 15, edited by J. L. Reid, pp. 169-203, American Geophysical Union, Washington, D. C.

Gordon, A. L., and P. L. Tchernia (1972), Waters of the continental margin off Adélie Coast, Antarctica, in Antarctic Research Series, vol. 19, edited by E. Hayes, pp. 59-69, American Geophysical Union, Washington, D. C.

Gordon, A. L., B. A. Huber, and J. Busecke (2015), Bottom water export from the western Ross Sea, 2007 through 2010, Geophysical Research Letters, 42(13), 5387-5394. doi:10.1002/2015GL064457.

Ha, H. K., et al. (2014), Circulation and Modification of Warm Deep Water on the Central Amundsen Shelf, Journal of Physical Oceanography, 44(5), 1493-1501. doi:10.1175/JPO-D-13-0240.1.

Herraiz-Borreguero, L., R. Coleman, I. Allison, S. R. Rintoul, M. Craven, and G. D. Williams (2015), Circulation of modified Circumpolar Deep Water and basal melt beneath the Amery Ice Shelf, East Antarctica: MCDW interaction with the Amery ice shelf, Journal of Geophysical Research: Oceans, 120(4), 3098-3112. doi:10.1002/2015JC010697.

Jacobs, S. (2006), Observations of change in the Southern Ocean, Philosophical Transactions of the Royal Society A: Mathematical, Physical and Engineering Sciences, 364(1844), 1657-1681. doi:10.1098/rsta. 2006.1794 .

Jacobs, S. S. (1989), Marine controls on modern sedimentation on the Antarctic continental shelf, Marine Geology, 85(2-4), 121-153. doi:10.1016/0025-3227(89)90151-5.

Jacobs, S. S. (1991), On the nature and significance of the Antarctic Slope Front, Marine Chemistry, 35(1-4), 9-24. doi:10.1016/S0304-4203(09)90005-6.

Jacobs, S. S. (2004), Bottom water production and its links with the thermohaline circulation, Antarctic Science, 16(4), 427-437. doi:10.1017/S095410200400224X.

Jacobs, S. S., A. F. Amos, and P. M. Bruchhausen (1970), Ross sea oceanography and antarctic bottom water formation, Deep Sea Research, 17(6), 935-962. doi:10.1016/0011-7471(70)90046-X.

Jacobs, S. S., H. H. Hellmer, and A. Jenkins (1996), Antarctic Ice Sheet melting in the southeast Pacific, Geophysical Research Letters, 23(9), 957-960. doi:10.1029/96GL00723.

Jacobsen, J., and A. J. Jensen (1926), Examination of hydrographic measurements from research vessels Explorer and Dana during the summer of 1924, Conseil Permanent International pour l'Exploration de la Mer, Rapports et Procs-Verbaux, 39, 31-84.

Journel, A., and C. Huijbregts (1978), Kriging geostatistics, Academic Press, New York.

Kunze, E., E. Firing, J. M. Hummon, T. K. Chereskin, and A. M. Thurnherr (2006), Global abyssal mixing inferred from lowered ADCP shear and CTD strain prooptfiles, Journal of Physical Oceanography, $36(8), 1553-1576$.

Kusahara, K., H. Hasumi, and G. D. Williams (2011), Dense shelf water formation and brine-driven circulation in the Adélie and George V Land region, Ocean Modelling, 37(3-4), 122-138. doi:10.1016/ j.ocemod.2011.01.008. 
Kusahara, K., H. Hasumi, A. D. Fraser, S.Aoki, K. Shimada, G.D. Williams, R. Massom, and T. Tamura (2017), Modeling ocean-cryosphere interactions off adélie and george $\mathrm{v}$ land, east antarctica, Journal of Climate, 30(1), 163-188. doi:10.1175/JCLI-D-15-0808.1.

Lacarra, M., M.-N. Houssais, E. Sultan, S. Rintoul, and C. Herbaut (2011), Summer hydrography on the shelf off Terre Adélie/George V Land based on the ALBION and CEAMARC observations during the IPY, Polar Science, 5(2), 88-103. doi:10.1016/j.polar.2011.04.008.

Lacarra, M., M.-N. Houssais, C. Herbaut, E. Sultan, and M. Beauverger (2014), Dense shelf water production in the Adélie Depression, East Antarctica, 2004-2012: Impact of the Mertz Glacier calving, Journal of Geophysical Research: Oceans, 119(8), 5203-5220. doi:10.1002/2013JC009124.

Legrésy, B., A. Wendt, I. Tabacco, F. Rémy, and R. Dietrich (2004), Influence of tides and tidal current on Mertz Glacier, Antarctica, Journal of Glaciology, 50(170), 427-435. doi:10.3189/172756504781829828.

Lescarmontier, L. (2012), Studies of the processes of fracturing, deformation and iceberg calving in Antarctica: A history of the Mertz Glacier. Etude des processus de fracturation, déformation et vlage d'iceberg en Antarctique: Une histoire du glacier Mertz.

Liu, Y., J. C. Moore, X. Cheng, R. M. Gladstone, J. N. Bassis, H. Liu, J. Wen, and F. Hui (2015), Ocean-driven thinning enhances iceberg calving and retreat of Antarctic ice shelves, Proceedings of the National Academy of Sciences, 112(11), 3263-3268. doi:10.1073/pnas.1415137112.

Lytle, V. I., A. P. Worby, R. Massom, M. J. Paget, I. Allison, X. Wu, and A. Roberts (2001), Ice formation in the Mertz Glacier polynya, East Antarctica, during winter, Annals of Glaciology, 33, 368-372. doi:10.3189/172756401781818464.

Martinson, D. G., S. E. Stammerjohn, R. A. Iannuzzi, R. C. Smith, and M. Vernet (2008), Western Antarctic Peninsula physical oceanography and spatiotemporal variability, Deep Sea Research Part II: Topical Studies in Oceanography, 55 (18-19), 1964-1987. doi:10.1016/j.dsr2.2008.04.038.

Matheron, G. (1963), Principles of geostatistics, Economic Geology, 58(8), 1246-1266. doi:10.2113/ gsecongeo.58.8.1246.

Mayet, C., L. Testut, B. Legresy, L. Lescarmontier, and F. Lyard (2013), High-resolution barotropic modeling and the calving of the Mertz Glacier, East Antarctica: Barotropic Modeling And The Calving Of The Mertz Glacier, Journal of Geophysical Research: Oceans, 118(10), 5267-5279. doi:10.1002/ jgrc.20339.

McIntosh, P. C., and S. R. Rintoul (1997), Do Box Inverse Models Work?, Journal of Physical Oceanography, 27(2), 291-308. doi:10.1175/1520-0485(1997)027〈0291:DBIMW〉2.0.CO;2.

Meredith, M. P. (2013), Oceanography: Replenishing the abyss, Nature Geoscience, 6(3), 166-167. doi: $10.1038 /$ ngeo1743.

Moffat, C., B. Owens, and R. C. Beardsley (2009), On the characteristics of Circumpolar Deep Water intrusions to the west Antarctic Peninsula Continental Shelf, Journal of Geophysical Research, 114(C5). doi:10.1029/2008JC004955.

Naveira Garabato, A. C., D. P. Stevens, and K. J. Heywood (2003), Water mass conversion, fluxes, and mixing in the Scotia Sea diagnosed by an inverse model, Journal of Physical Oceanography, 33(12), $2565-2587$.

Nicol, S., T. Pauly, N. L. Bindoff, S. Wright, D. Thiele, G. W. Hosie, P. G. Strutton, and E. Woehler (2000), Ocean circulation off east Antarctica affects ecosystem structure and sea-ice extent, Nature, 406 (6795), 504-507. doi:10.1038/35020053.

Orsi, A. H. (2010), Oceanography: Recycling bottom waters, Nature Geoscience, 3(5), 307-309. doi: $10.1038 /$ ngeo854.

Orsi, A. H., T. Whitworth, and W. D. Nowlin (1995), On the meridional extent and fronts of the Antarctic Circumpolar Current, Deep Sea Research Part I: Oceanographic Research Papers, 42(5), 641-673. doi: 10.1016/0967-0637(95)00021-W. 
Orsi, A. H., G. C. Johnson, and J.L.Bullister (1999), Circulation, mixing, and production of Antarctic Bottom Water, Progress in Oceanography, 43(1), 55-109.

Pawlowicz, R., B. Beardsley, and S. Lentz (2002), Classical tidal harmonic analysis including error estimates in MATLAB using T_tide, Computers \& Geosciences, 28(8), 929-937. doi:10.1016/ S0098-3004(02)00013-4.

Pritchard, H. D., S. R. M. Ligtenberg, H. A. Fricker, D. G. Vaughan, M. R. van den Broeke, and L. Padman (2012), Antarctic ice-sheet loss driven by basal melting of ice shelves, Nature, 484(7395), 502-505. doi:10.1038/nature10968.

Purkey, S. G., and G. C. Johnson (2013), Antarctic Bottom Water Warming and Freshening: Contributions to Sea Level Rise, Ocean Freshwater Budgets, and Global Heat Gain, Journal of Climate, 26 (16), 6105-6122. doi:10.1175/JCLI-D-12-00834.1.

Rignot, E. (2002), Rapid Bottom Melting Widespread near Antarctic Ice Sheet Grounding Lines, Science, 296(5575), 2020-2023. doi:10.1126/science.1070942.

Rignot, E., I. Velicogna, M. R. van den Broeke, A. Monaghan, and J. T. M. Lenaerts (2011), Acceleration of the contribution of the Greenland and Antarctic ice sheets to sea level rise, Geophysical Research Letters, 38(5). doi:10.1029/2011GL046583.

Rignot, E., S. Jacobs, J. Mouginot, and B. Scheuchl (2013), Ice-Shelf Melting Around Antarctica, Science, 341(6143), 266-270. doi:10.1126/science.1235798.

Rintoul, S. R. (1998), On the origin and influence of Adélie land bottom water, in Antarctic Research Series, vol. 75, edited by S. S. Jacobs and R. F. Weiss, pp. 151-171, American Geophysical Union, Washington, D. C.

Rintoul, S. R. (2007), Rapid freshening of Antarctic Bottom Water formed in the Indian and Pacific oceans, Geophysical Research Letters, 34(6). doi:10.1029/2006GL028550.

Rodrigo, J., J.-M. Buchlin, J. van Beeck, J. T. M. Lenaerts, and M. R. van den Broeke (2013), Evaluation of the antarctic surface wind climate from ERA reanalyses and RACMO2/ANT simulations based on automatic weather stations, Climate Dynamics, 40(1-2), 353-376. doi:10.1007/s00382-012-1396-y.

Rosenberg, M., and S. R. Rintoul (2010), Aurora Australis Marine Science Cruises AU0803 and AU0806Oceanographic Field Measurements and Analysis, Technical report, Antarct. Clim. and Ecosyst. Coop. Res. Cent., Hobart.

Sambrotto, R. N., A. Matsuda, R. Vaillancourt, M. Brown, C. Langdon, S. S. Jacobs, and C. Measures (2003), Summer plankton production and nutrient consumption patterns in the Mertz Glacier Region of East Antarctica, Deep Sea Research Part II: Topical Studies in Oceanography, 50(8-9), 1393-1414. doi:10.1016/S0967-0645(03)00076-6.

Schmidtko, S., K. J. Heywood, A. F. Thompson, and S. Aoki (2014), Multidecadal warming of Antarctic waters, Science, 346(6214), 1227-1231. doi:10.1126/science.1256117.

Sloyan, B. M., and S. R. Rintoul (2000), Estimates of area-averaged diapycnal fluxes from basin-scale budgets, Journal of Physical Oceanography, 30(9), 2320-2341.

Smith, W. O., M. S. Dinniman, E. E. Hofmann, and J. M. Klinck (2014), The effects of changing winds and temperatures on the oceanography of the Ross Sea in the 21st century: MODELED FUTURE ROSS SEA CHANGES, Geophysical Research Letters, 41(5), 1624-1631. doi:10.1002/2014GL059311.

Snow, K., B. Sloyan, S. Rintoul, A. Hogg, and S. Downes (2016), Controls on circulation, cross-shelf exchange, and dense water formation in an antarctic polynya, Geophysical Research Letters, 43(13), 7089-7096. doi:10.1002/2016GL069479.

Spence, P., S. M. Griffies, M. H. England, A. M. Hogg, O. A. Saenko, and N. C. Jourdain (2014), Rapid subsurface warming and circulation changes of Antarctic coastal waters by poleward shifting winds, Geophysical Research Letters. doi:10.1002/2014GL060613. 
Spreen, G., L. Kaleschke, and G. Heygster (2008), Sea icerremotesensing using AMSR-E 89-GHz channels, Journal of Geophysical Research, 113(C2). doi:10.1029/2005JC003384.

Stewart, A. L., and A. F. Thompson (2015), Eddy-mediated transport of warm Circumpolar Deep Water across the Antarctic Shelf Break, Geophysical Research Letters, 42(2), 432-440. doi:10.1002/ 2014 GL062281.

Tamura, T., K. I. Ohshima, and S. Nihashi (2008), Mapping of sea ice production for Antarctic coastal polynyas:, Geophysical Research Letters, 35(7). doi:10.1029/2007GL032903.

Tamura, T., G. Williams, A. Fraser, and K. Ohshima (2012), Potential regime shift in decreased sea ice production after the Mertz Glacier calving, Nature Communications, 3, 826. doi:10.1038/ncomms1820.

Thompson, A. F., K. J. Heywood, S. Schmidtko, and A. L. Stewart (2014), Eddy transport as a key component of the Antarctic overturning circulation, Nature Geoscience, 7(12), 879-884. doi:10.1038/ ngeo2289.

Tomczak, M. (1981), A multi-parameter extension of temperature/salinity diagram techniques for the analysis of non-isopycnal mixing, Progress in Oceanography, 10(3), 147-171. doi:10.1016/0079-6611(81) 90010-0

Vaillancourt, R. D., R. N. Sambrotto, S. Green, and A. Matsuda (2003), Phytoplankton biomass and photosynthetic competency in the summertime Mertz Glacier Region of East Antarctica, Deep Sea Research Part II: Topical Studies in Oceanography, 50(8-9), 1415-1440. doi:10.1016/S0967-0645(03) 00077-8.

Whitworth, T., A. H. Orsi, S.-J. Kim, W. D. Nowlin, and R. A. Locarnini (1998), Water masses and mixing near the Antarctic Slope Front, Ocean, ice, and atmosphere: interactions at the Antarctic continental margin, pp. 1-27.

Williams, G., and N. Bindoff (2003), Wintertime oceanography of the Adélie Depression, Deep Sea Research Part II: Topical Studies in Oceanography, 50(8-9), 1373-1392. doi:10.1016/S0967-0645(03) 00074-2.

Williams, G. D., N. L. Bindoff, S. J. Marsland, and S. R. Rintoul (2008), Formation and export of dense shelf water from the Adélie Depression, East Antarctica, Journal of Geophysical Research, 113(C4). doi:10.1029/2007JC004346.

Williams, G. D., S. Aoki, S. S. Jacobs, S. R. Rintoul, T. Tamura, and N. L. Bindoff (2010), Antarctic Bottom Water from the Adélie and George V Land coast, East Antarctica (140-149 ${ }^{\circ}$ ), Journal of Geophysical Research, 115(C4). doi:10.1029/2009JC005812.

Williams, G. D., M. Hindell, M.-N. Houssais, T. Tamura, and I. C. Field (2011), Upper ocean stratification and sea ice growth rates during the summer-fall transition, as revealed by Elephant seal foraging in the Adélie Depression, East Antarctica, Ocean Science, 7(2), 185-202. doi:10.5194/os-7-185-2011.

Wunsch, C. (1978), The North Atlantic general circulation west of $50^{\circ} \mathrm{W}$ determined by inverse methods, Reviews of Geophysics, 16(4), 583-620. doi:10.1029/RG016i004p00583.

Wunsch, C. (1996), The ocean circulation inverse problem, Cambridge University Press, Cambridge ; New York.

Wunsch, C. (2006), Discrete inverse and state estimation problems: with geophysical fluid applications, Cambridge University Press, Cambridge ; New York.

Zwally, H. J., J. C. Comiso, and A. L. Gordon (1985), Antarctic offshore leads and polynyas and oceanographic effects, in Antarctic Research Series, vol. 43, edited by S. Jacobs, pp. 203-226, American Geophysical Union, Washington, D. C. 